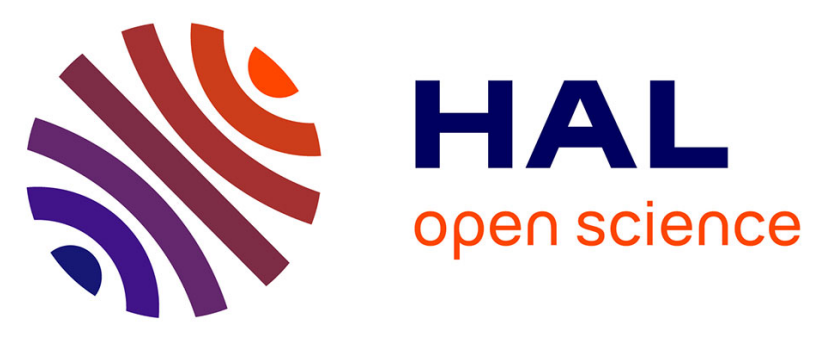

\title{
Subthalamus stimulation in Parkinson disease: Accounting for the bilaterality of contacts
}

\author{
Jean-Jacques Lemaire, Bruno Pereira, Philippe Derost, François Vassal, \\ Miguel Ulla, Dominique Morand, Guillaume Coll, Jean J Gabrillargues, Ana \\ Marques, Bérangère Bebilly, et al.
}

\section{To cite this version:}

Jean-Jacques Lemaire, Bruno Pereira, Philippe Derost, François Vassal, Miguel Ulla, et al.. Subthalamus stimulation in Parkinson disease: Accounting for the bilaterality of contacts. Surgical Neurology International, 2016, 7, pp.S837-S847. 10.4103/2152-7806.194066 . hal-01558126

\author{
HAL Id: hal-01558126 \\ https://hal.uca.fr/hal-01558126
}

Submitted on 7 Jul 2017

HAL is a multi-disciplinary open access archive for the deposit and dissemination of scientific research documents, whether they are published or not. The documents may come from teaching and research institutions in France or abroad, or from public or private research centers.
L'archive ouverte pluridisciplinaire HAL, est destinée au dépôt et à la diffusion de documents scientifiques de niveau recherche, publiés ou non, émanant des établissements d'enseignement et de recherche français ou étrangers, des laboratoires publics ou privés.

\section{(ㅇ)(1) $\$$}

Distributed under a Creative Commons Attribution - NonCommerciall 4.0 International 


\title{
Subthalamus stimulation in Parkinson disease: Accounting for the bilaterality of contacts
}

Jean-Jacques Lemaire ${ }^{1,2}$, Bruno Pereira ${ }^{2,3}$, Philippe Derost ${ }^{4}$, François Vassal ${ }^{2}$, Miguel Ulla ${ }^{4}$, Dominique Morand ${ }^{3}$, Guillaume Coll1,2, Jean Gabrillargues ${ }^{1,5}$, Ana Marques ${ }^{4}$, Bérangère Debilly ${ }^{4}$, Jérôme Coste ${ }^{1,2}$, Franck Durif ${ }^{4}$

${ }^{1}$ Service of Neurosurgery, Gabriel Montpied Hospital, University Hospital of Clermont-Ferrand, Clermont-Ferrand, ${ }^{2}$ Image-Guided Clinical Neuroscience and Connectomics, Research Team, Auvergne University, Auvergne, ${ }^{3}$ Biostatistics, Clinical Research Direction, Gabriel Montpied Hospital, University Hospital of Clermont-Ferrand, Clermont-Ferrand, ${ }^{4}$ Service of Neurology, Gabriel Montpied Hospital, University Hospital of Clermont-Ferrand, Clermont-Ferrand, ${ }_{5}^{5}$ Service of Radiology, Neuroradiology Unit, Gabriel Montpied Hospital, University Hospital of Clermont-Ferrand, Clermont-Ferrand, France

E-mail: *Jean-Jacques Lemaire - jeanjacques.lemaire@gmail.com; Bruno Pereira - bpereira@chu-clermontferrand.fr; Philippe Derost - pderost@chu-clermontferrand.fr; François Vassal - francoisvassal@wanadoo.fr; Miguel Ulla - mulla@chu-clermontferrand.fr; Dominique Morand - dmorand@chu-clermontferrand.fr; Guillaume Coll-gcoll@chu-clermontferrand.fr; Jean Gabrillargues - jgabrillargues@chu-clermontferrand.fr; Ana Marques - anamarques6@yahoo.fr; Bérangère Debilly - bdebilly@chu-clermontferrand.fr; Jérôme Coste - jcoste@ chu-clermontferrand.fr; Franck Durif - fdurif@chu-clermontferrand.fr *Corresponding author

Received: 08 January $16 \quad$ Accepted: 27 May $16 \quad$ Published: 14 November 16

\begin{abstract}
Background: Deep brain stimulation (DBS) in Parkinson's disease uses bi-hemispheric high-frequency stimulation within the subthalamus, however, the specific impacts of bilaterality of DBS are still not clear. Thus, we aimed to study the individual-level clinical impact of locations of right-left contact pair-up accounting for each subthalamic nucleus (STN) anatomy.

Methods: Contact locations and effects at 1 year were studied retrospectively in an unselected series of 53 patients operated between 2004 and 2010. Location of contacts was defined relatively to the main axis of STN used to map longitudinal and transversal positions, and STN membership (out meaning out-of-STN). Contact pairings were described via three methods: (i) Unified contact location (UCL) collapsing DBS into an all-in-one contact; (ii) balance of contact pair-up (BCPU), defined as symmetric or asymmetric regardless of laterality; (iii) hemisphere-wise most frequent contact pair-up (MFCP) regardless of BCPU. Clinical data were: mean levodopa equivalent dose, Unified Parkinson's Disease Rating Scale (UPDRS) motor score III without medication, UPDRS II and III speech sub-scores, UPDRS II freezing sub-score, 1 year versus preoperative values, with and without levodopa. Ad-hoc two-sided tests were used for statistical analysis.

Results: Worsening speech, was more frequent for UCL_out patients and when the left MFCP contact was rear and/or superolateral, however, it less frequent for $\mathrm{BCPU}$-asymmetric patients. Worsening freezing was more frequent when the right MFCP contact was rear and superolateral.
\end{abstract}

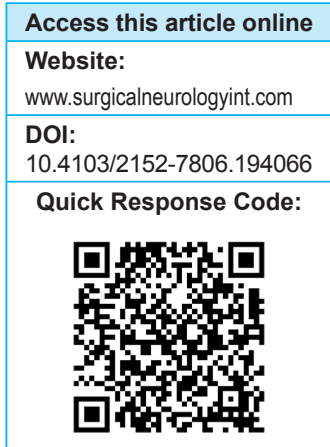

This is an open access article distributed under the terms of the Creative Commons Attribution-NonCommercial-ShareAlike 3.0 License, which allows others to remix, tweak, and build upon the work non-commercially, as long as the author is credited and the new creations are licensed under the identical terms.

For reprints contact: reprints@medknow.com

How to cite this article: Lemaire JJ, Pereira B, Derost P,Vassal F, Ulla M, Morand D, et al. Subthalamus stimulation in Parkinson disease:Accounting for the bilaterality of contacts. Surg Neurol Int 2016;7:S837-47.

http://surgicalneurologyint.com/Subthalamus-stimulation-in-Parkinson-disease:-Accounting-for-the-bilaterality-of-contacts/ 
Conclusions: These results point to strategies for minimizing dysarthria and freezing as adverse effects of DBS.

Key Words: Bilateral, deep brain stimulation, Parkinson's disease, Subthalamic nucleus

\section{INTRODUCTION}

Bilateral high-frequency chronic deep brain stimulation (DBS) of the subthalamic nucleus (STN) is an efficient treatment for motor complications in advanced Parkinson's disease $^{[1,23,24]}$ and a promising option for younger patients. $^{[30]}$ Motor efficiency, commonly quantified as the percent reduction of Unified Parkinson's Disease Rating Scale motor score III (UPDRS III; from 0 to 108, where higher values equate to more severe symptoms) without medication, ranges, on average, from 35.8 to $61 \%$ [Figure la]. This broad variability across studies

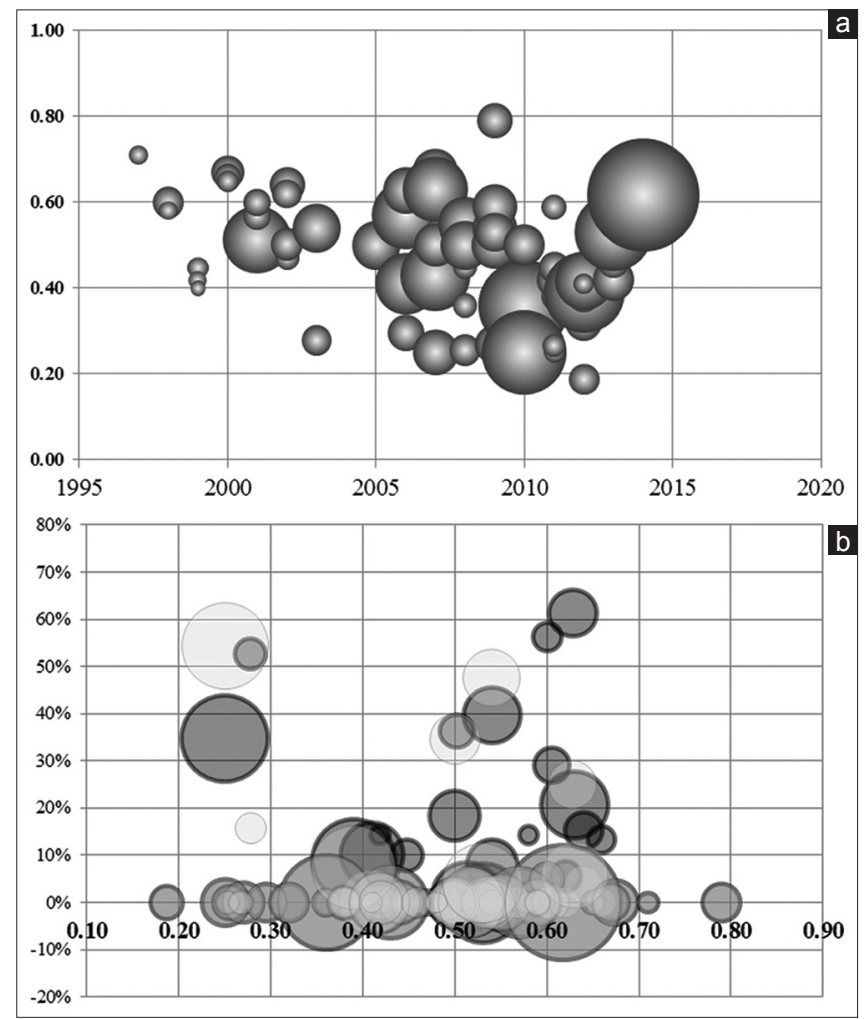

Figure I: Overview of literature from 1994 to 20 I4: Bilateral, high-frequency, chronic deep brain stimulation (DBS) of the subthalamic nucleus (STN), or "STN DBS." (a) Percent reduction of Unified Parkinson's Disease Rating Scale motor score III (y-axis) according to the year of publication; the circle size is proportional to number of patients in the series $(n=72)$. (b) Distribution of stimuli-induced adverse effects ( $y$-axis; percentage of patients with speech worsening, grey circles, or postural worsening, white circles; circle size is proportional to number of patients in the series) according to the percent drop in Unified Parkinson's Disease Rating Scale motor score III without medication (x-axis) in the series (40 and 41 did not reported stimuli-induced adverse effects, respectively for speech and posture; out of 72 ) is difficult to explain but fits with the inter-individual variability observed in daily practice. It depends on several parameters that, although not fully grasped, include phenotype of Parkinson's disease, comorbidities, age, duration and severity of disease, sociofamilial context, goal-directed postoperative management, surgical lesion, electrode design, current delivery, contact positioning, and specificity of the anatomo-functional environment of each individual. Motor improvement seems to rely mainly on STN modulation, ${ }^{[1]}$ which also triggers adverse effects such as deterioration in speech intelligibility, ${ }^{[8,33]}$ particularly in the posterior region of the STN, ${ }^{[17]}$ whereas pitch voice modifications, ${ }^{[16]}$ such as gait worsening, ${ }^{[28]}$ seem less frequent with posterior (caudal) zona incerta. Adverse effects are rarely documented. Approximately $46 \%$ of studies report adverse event data, of which $62.5 \%$ report speech worsening and $37.5 \%$ postural worsening, both of which are independent of aggregate motor efficiency [Figure lb]. The overall mechanism of action of STN DBS is still intriguing. ${ }^{[2,7,9,23,24]}$ Location of contacts is likely a pivotal factor given the functional segregation of the STN ${ }^{[22,15,12]}$ and its anatomic environment. ${ }^{[21]}$ New DBS technologies will likely help factor in the specificity of individual anatomy and functionality. ${ }^{[1]}$ In practice, STN DBS involves the STN and its close vicinity because clinical improvement has been reported within an anteroposterior area encompassing the superior border of the STN, ${ }^{[39]}$ the fields of Forel, and the zona incerta. ${ }^{[3,10,27,35]}$ Globally, the explanation of the clinical effects of bilateral STN DBS is simplified as if the location of the effective right and left contacts is symmetrical and collapsible into a unique location including the STN and its close environment.

We hypothesized that accounting for each individual right-left contact pair-up could be relevant to study either positive or adverse clinical effects for further personalization of electrode targeting and optimization of pulse settings. Here, we performed a single-center cross-sectional cohort study of 53 consecutive unselected patients, analyzing aggregate motor efficiency, dysarthria, and freezing according to the location of effective contacts used in chronic conditions at 1 year post-surgery. In addition, we analyzed the influence of age, gender, voltage, and drug modifications. We assumed an optimal compromise between medical treatment and bilateral DBS for each individual. Location of effective contacts was blinded from clinical results. Each right-left pair-up 
of effective contacts was specified according to STN landmarks, enabling two analyses, namely, a unified approach, where right-left contact pair-up was simplified, resulting in a unique location for each individual, and a bilateral approach, describing the balance of right-left contact pair-up for each patient and accounting for differences between the right and left hemispheric locations.

\section{MATERIALS AND METHODS}

\section{Patients}

Clinical data on 53 Parkinson's patients (two left-handed) operated consecutively between June 2004 and September 2010 were studied retrospectively after first securing Institutional Review Board approval. Bilateral subthalamic DBS (Lead 3387@), Kinetra@); Medtronic, USA) implantation was carried out according to the preoperative magnetic resonance imaging (MRI) anatomic mapping and intraoperative micro-recordings and clinical assessment (rigidity, tremor, speech) using semi-micro stimulation (MicroGuide Pro ${ }^{\mathrm{TM}}$; Alpha Omega, Israel) following an already published technique. ${ }^{[6,18]}$ The four lead contacts were usually positioned as follows (double obliquity avoiding vessels, sulci, ventricles, striatum; entry point within the second frontal gyrus): Contact 0 (distal) within the STN, typically near the center; contact 1 within the lateral and superior region of the STN, at the frontier or outside, i.e., within the fields of Forel or zona incerta; contact 2 within the fields of Forel or zona incerta; contact 3 (proximal) within the inferior portion of the ventral-lateral thalamus. Contact number 1 was placed on the optimal site allowing efficacy on symptoms with a low current value (usually between 0.2 and $1 \mathrm{~mA}$ ) and no or little adverse effects with a high current value (usually above $2 \mathrm{~mA}$ ), using semi-micro electrodes. The final locations of the right and left electrodes, particularly in the anteroposterior position, depended on anatomy (limiting the options for secured trajectories), intraoperative assessments, and technical concerns such as mechanical accuracy of stereotactic tools. Brain shift was negligible with this technique (X-ray and computed tomography (CT)-scan controls; recumbent position; cerebrospinal-fluid-air-proof dura opening). All patients attended regular follow-up with senior institutional neurologists at least 1 year after the surgery to optimize their medication and pulse settings. UPDRS II, III, and IV sub-scores at 1 year post-implantation were collected [Table 1].

Motor efficiency on the targeted motor symptoms was calculated on UPDRS III motor score, and expressed as percent improvement, in Dopa-OFF condition (MedOFF) at 1 year: StimOFFlyr - StimONlyr/StimOFFlyr; Dopa challenge, DopaOFF, 12 hours after withdrawal of antiparkinsonian drugs; StimOFF, 1 hour after turning
Table 1: Demographic data of the 53 Parkinson's patients operated on consecutively between June 2004 and September 2010; (a) Baseline characteristics; (b) 1-year follow-up

Values

(a) Baseline characteristics

Age (years) (mean $\pm S E)$

$60.9 \pm 7.4$

Gender, $n(\%)$

Male

$30(56.6)$

Duration of Parkinson's disease (years) (mean \pm SE)

$10.9 \pm 4.3$

UPDRS IV duration of "Dyskinesia" sub-score $(n=53)$,

duration (mean $\pm S E$ )

UPDRS IV duration of "off phases" sub-score $(n=53)$, duration (mean $\pm S E$ )

Treatment with levodopa $(n=53)$, dose (mean \pm SE)

Treatment with dopamine agonist $(n=37)$,

dose (mean \pm SE)

Levodopa-equivalent daily dose $(\mathrm{mg})$ (mean $\pm \mathrm{SE})$

UPDRS III global (mean \pm SE)

Med ON

Med OFF

UPDRS II speech sub-score (mean \pm SE)

Med ON

$1.7 \pm 1.0$

$1.6 \pm 0.7$

Med OFF

UPDRS III speech sub-score (mean \pm SE)

Med ON

Med OFF

UPDRS II freezing sub-score (mean \pm SE)

Med ON

$960.2 \pm 434.4$

$182.7 \pm 176.6$

$1182.3 \pm 411$

$8.4 \pm 4.9$

$29.6 \pm 9.8$

$0.4 \pm 0.7$

$0.9 \pm 0.9$

$0.4 \pm 0.6$

$0.7 \pm 0.7$

$0.2 \pm 0.5$

$1.0 \pm 1.2$

(b) 1 year follow-up

Levodopa-equivalent daily dose $(\mathrm{mg})(\mathrm{mean} \pm \mathrm{SE})$

$1051.3 \pm 566$

UPDRS IV duration of "Dyskinesia" sub-score $(n=53)$, duration (mean $\pm S E$ )

UPDRS IV duration of "off phases" sub-score $(n=53)$, duration (mean $\pm S E$ )

UPDRS III global $(n=53)$ (mean \pm SE)

Med ON Stim ON

$14.0 \pm 8.3$

Med ON Stim OFF

$14.9 \pm 10.0$

Med OFF Stim ON

$22.9 \pm 10.2$

Med OFF Stim OFF

$37.7 \pm 13,2$

Score improvement $(n=53)$ (Med OFF, $n)$

Low, $<30 \%$

12

Moderate, $(30 \%, 50 \%)$

28

High, $>50 \%$

13

UPDRS II speech sub-score, chronic $(n=53)($ mean \pm SE)

Med ON

Med OFF

$1,6 \pm 1,0$

$1.7 \pm 0,9$

UPDRS III speech sub-score, acute $(n=53)$ (mean \pm SE)

Med ON Stim ON

$1.5 \pm 0.9$

Med ON Stim OFF

$1.3 \pm 0.8$

Med OFF Stim ON

$1.5 \pm 0.8$

Med OFF Stim OFF 
Table 1: Contd...

\begin{tabular}{ll}
\hline & Values \\
\hline UPDRS II freezing sub-score, chronic $(n=53)($ mean \pm SE) & \\
Med ON & $0.5 \pm 0.7$ \\
Med OFF & $1.1 \pm 1.2$ \\
\hline
\end{tabular}

UPDRS: Unified Parkinson's Disease Rating Scale, Med On: With medication, Med OFF:Without medication, Stim ON: Bilateral deep brain stimulation ON with the effective contacts used in chronic conditions I year after surgery, SE: Standard error

off the stimulator; stimON, using the chronic parameters at 1 year (substantial clinical improvement; compromise with any adverse effects; optimized dopatherapy). Mean percent UPDRS III improvement in Dopa-OFF condition was $37.1 \%$ [Table lb]. Disease severity increased over 1 year, with UPDRS III score in DopaOFF-StimOFF conditions varying from $29.6 \pm 9.8$ to $37.7 \pm 13.2$ (paired $t$-test; $P<0.001$ ). For group analysis, percent DBS motor improvement was segregated into three classes [Table $1 \mathrm{~b}$ ] as low, $<30 \%, 12$ patients (22.6\%); moderate, from 30 to $50 \%, 28$ patients $(52.8 \%)$, and high, $>50 \%, 13$ patients (24.5\%). UPDRS IV sub-scores on dyskinesia and off-phases at 1 year were significantly reduced [Table la; $P<0.001]$. We used UPDRS II and III sub-scores describing speech and freezing [Table 1S]: 0, no speech problems or freezing; 1, slight symptoms; 2, mild symptoms; 3, moderate symptoms; 4, severe symptoms. Speech was explored with and without medication as follows: 1-year versus preoperative values of UPDRS II speech sub-score based on spontaneous fluctuations (or chronic condition) and UPDRS III speech sub-score in acute condition; at 1 year, stimON versus stimOFF. Freezing was quantified as follows: l-year versus preoperative values of UPDRS II freezing sub-score based on spontaneous fluctuations when walking (or chronic conditions) with and without medication. Modifications in UPDRS sub-scores on speech and freezing were segregated into three classes according to two modalities: Option A, less sensitive to worsening, improvement, $\leq 0$; no change $[0,1]$ or $0.5-1$; worsening $>1$; option $\mathrm{B}$ more sensitive to worsening, improvement, $\leq 0$; no change, $[0,1]$ or 0.5 ; worsening, $\geq 1$. Patient distribution according to these criteria is reported in Table 2.

Right-plus-left l-year effective contacts $(n=106)$ were: 10 times contact $0(9.4 \%), 49$ times contact 1 (46.2\%), and 42 times contact 2 (39.6\%), thus, $95.3 \%$ of contacts were within the subthalamus; and 5 times contact $3(4.7 \%)$. The average ( \pm SEM; median) and min-max l-year voltage values (monopolar stimulation 102 times out of $106 ; 130 \mathrm{~Hz})$ of right and left contacts were $2.92 \mathrm{~V}( \pm 0.98$; $2.80), 1.00-6.30$ and $2.98 \mathrm{~V}( \pm 0.87 ; 2.80), 1.30-6.30$, respectively, with no significance difference between the two sides $(P=0.58$, paired $t$-test). For further analysis, voltage difference, left minus right, and absolute value of difference for each individual (mean \pm SEM; median; min-max) were calculated as: Left minus right $=0.06 \mathrm{~V}$
$( \pm 0.76 ; 0.00)$, min $-2 \mathrm{~V}$, ma $\times 2.80 \mathrm{~V}$; the absolute value of difference $0.44 \mathrm{~V}( \pm 0.62 ; 0.20)$, min $0 \mathrm{~V}$, ma $\times 2.80$ $\mathrm{V}$. Mean variation in levodopa equivalent drugs (LED) expressed as percent LED variation, i.e. preoperative dose - l-year postoperative dose/preoperative dose $(n=50,3$ missing data) was $0.1 \pm 0.5$ ( $\mathrm{min}=-1.7$; $\max$ $=0.8$, with a positive value indicating a drop in LED. For further analysis, the percentages of LED variation were segregated into three classes: $<-30 \%$, significant rise, 8 patients; $[-30 \%, 30 \%]$, no significant change, 23 patients; $>30 \%$, significant drop, 19 patients.

Location of effective contacts according to subthalamic nucleus landmark

Location of effective contacts (chronic stimulation 1 year after electrode implantation) was determined for the right and left hemispheres. Each contact was identified on postoperative CT $\operatorname{scan}^{[13]}$ co-registered with preoperative MRI (Iplan (), BrainLab, Germany). STN had already been contoured preoperatively on coronal stereotactic MRI slices acquired with a dedicated anatomic sequence called White Matter Attenuated Inversion Recovery (WAIR), at 2-mm slice thickness and a pixel size of $0.56 \times 0.56 \mathrm{~mm}^{2}$. The main STN axis running laterally and superiorly was used as reference to specify contact location. This axis was determined on preoperative MRIs using tri-planar and 3D display (Iplan@ , BrainLab, Germany). The geometric characteristics of the right and left STN, respectively, were: Mean length of main axis, $9.96 \mathrm{~mm}( \pm 1.76$; $\min , 6.91 ; \max 13.75)$ and $9.46 \mathrm{~mm}( \pm 1.60$; $\mathrm{min}, 5.79$; $\max 13.13)$; mean volume, $0.14 \mathrm{~cm}^{3}( \pm 0.04 ; \min , 0.06$; $\max 0.23)$ and $0.13 \mathrm{~cm}^{3}$ $( \pm 0.04 ; \min , 0.06 ; \max 0.22)$. The anatomic space around the main axis was parceled for further analysis [Figures 2 and 3]. It was subdivided into 4 longitudinal anteroposterior subdivisions along the axis, i.e., front, intermediate-anterior (InterAnt), intermediate-posterior (InterPost), and rear, and 4 transversal subdivisions in the plane perpendicular to axis, i.e. superolateral (SupLat), superomedial (SupMed), inferolateral (InfLat) and inferomedial (InfMed). Contacts were attributed to several subdivisions as each contact was mapped because a 3-mm-diameter circle to integrate geometric errors and contact dimensions (length, $1.5 \mathrm{~mm}$ : Diameter, $1.3 \mathrm{~mm}$ ). Thus, a total 7 longitudinal and 8 transversal, discrete, contact locations were defined: 4 longitudinal primary, Front, InterAnt, InterPost and Rear; 3 longitudinal combined, InterAnt/Front, InterPost/InterAnt and Rear/ InterPost; 4 transversal primary, SupLat, InfLat, InfMed and SupMed; 4 transversal combined, SupLat/InfLat, InfLat/InfMed, SupMed/InfMed, and SupLat/SupMed. Contact location was also specified according to STN contour defining STN membership, i.e. within (In), at the frontier (Frontier), or outside (Out) the STN. Hence, for each patient, right and left contact locations were characterized by longitudinal and transversal positions 
Table 2: Distribution of patients according to the modifications of Unified Parkinson's Disease Rating Scores, following bilateral subthalamic deep brain stimulation: option $A$, less sensitive to worsening; option $B$, more sensitive to worsening; (a) Unified Parkinson's Disease Rating Scores II speech sub-score; (b) Unified Parkinson's Disease Rating Scores III speech sub-score; (c) Unified Parkinson's Disease Rating Scores freezing sub-score

\begin{tabular}{|c|c|}
\hline (a) Modifications of UPD & $n$ \\
\hline \multicolumn{2}{|c|}{1 year versus preoperative, Med ON ( $n=48)$} \\
\hline \multicolumn{2}{|l|}{ Option A } \\
\hline Improvement, $\leq 0$ & 13 \\
\hline No change, $0.5-1$ & 16 \\
\hline Worsening, $>1$ & 19 \\
\hline \multicolumn{2}{|l|}{ Option B } \\
\hline Improvement, $\leq 0$ & 13 \\
\hline No change, 0.5 & 0 \\
\hline Worsening, $\geq 1$ & 35 \\
\hline \multicolumn{2}{|c|}{1 year versus preoperative, Med OFF $(n=47)$} \\
\hline \multicolumn{2}{|l|}{ Option A } \\
\hline Improvement, $\leq 0$ & 14 \\
\hline No change, $0.5-1$ & 22 \\
\hline Worsening, $>1$ & 11 \\
\hline \multicolumn{2}{|l|}{ Option B } \\
\hline Improvement, $\leq 0$ & 14 \\
\hline No change, 0.5 & 2 \\
\hline Worsening, $\geq 1$ & 31 \\
\hline \multicolumn{2}{|c|}{ (b) Modifications of UPDRS III speech sub-score } \\
\hline \multicolumn{2}{|c|}{1 year versus preoperative, Med ON $(n=50)$} \\
\hline \multicolumn{2}{|l|}{ Option A } \\
\hline Improvement, $\leq 0$ & 14 \\
\hline No change, $0.5-1$ & 20 \\
\hline Worsening, $>1$ & 16 \\
\hline \multicolumn{2}{|l|}{ Option B } \\
\hline Improvement, $\leq 0$ & 14 \\
\hline No change, 0.5 & 4 \\
\hline Worsening, $\geq 1$ & 32 \\
\hline \multicolumn{2}{|c|}{1 year versus preoperative, Med OFF $(n=53)$} \\
\hline \multicolumn{2}{|l|}{ Option A } \\
\hline Improvement, $\leq 0$ & 20 \\
\hline No change, $0.5-1$ & 21 \\
\hline Worsening, $>1$ & 12 \\
\hline \multicolumn{2}{|l|}{ Option B } \\
\hline Improvement, $\leq 0$ & 20 \\
\hline No change, 0.5 & 4 \\
\hline Worsening, $\geq 1$ & 29 \\
\hline \multicolumn{2}{|l|}{1 year, Med ON $(n=45)$} \\
\hline \multicolumn{2}{|l|}{ Option A } \\
\hline Improvement, $\leq 0$ & 13 \\
\hline No change, $0.5-1$ & 22 \\
\hline Worsening, $>1$ & 10 \\
\hline
\end{tabular}

Contd...
Table 2: Contd...

\begin{tabular}{|c|c|}
\hline \multicolumn{2}{|l|}{ Option B } \\
\hline Improvement, $\leq 0$ & 13 \\
\hline No change, 0.5 & 5 \\
\hline Worsening, $\geq 1$ & 27 \\
\hline \multicolumn{2}{|l|}{1 year, Med OFF $(n=53)$} \\
\hline \multicolumn{2}{|l|}{ Option A } \\
\hline Improvement, $\leq 0$ & 22 \\
\hline No change, $0.5-1$ & 22 \\
\hline Worsening, $>1$ & 9 \\
\hline \multicolumn{2}{|l|}{ Option B } \\
\hline Improvement, $\leq 0$ & 22 \\
\hline No change, 0.5 & 4 \\
\hline Worsening, $\geq 1$ & 27 \\
\hline \multicolumn{2}{|c|}{ (c) Modifications of UPDRS II freezing sub-score } \\
\hline \multicolumn{2}{|c|}{1 year versus preoperative, Med ON $(n=47)$} \\
\hline \multicolumn{2}{|l|}{ Option A } \\
\hline Improvement, $\leq 0$ & 35 \\
\hline No change, $0.5-1$ & 9 \\
\hline Worsening, $>1$ & 3 \\
\hline \multicolumn{2}{|l|}{ Option B } \\
\hline Improvement, $\leq 0$ & 35 \\
\hline No change, 0.5 & 0 \\
\hline Worsening, $\geq 1$ & 12 \\
\hline \multicolumn{2}{|c|}{1 year versus preoperative, Med OFF $(n=48)$} \\
\hline \multicolumn{2}{|l|}{ Option A } \\
\hline Improvement, $\leq 0$ & 31 \\
\hline No change, $0.5-1$ & 10 \\
\hline Worsening, $>1$ & 7 \\
\hline \multicolumn{2}{|l|}{ Option B } \\
\hline Improvement, $\leq 0$ & 31 \\
\hline No change, 0.5 & 0 \\
\hline Worsening, $\geq 1$ & 17 \\
\hline
\end{tabular}

Med On:With medication, Med OFF:Without medication, UPDRS: Unified Parkinson's Disease Rating Scale

and STN membership, thus yielding per-individual discrete contact locations. Most contacts at 1 year were in intermediate or posterior superolateral position and at the frontier or outside the STN [Figure 4 and Table 2S].

We defined a unified contact location (UCL) of right and left contacts for each patient because the so-called "STN DBS" unifies right and left contacts assuming no significant asymmetry. The 53 patients were regrouped according to simplified longitudinal (Front, Intermediate, and Rear) and transversal (SuperoLateral, SupLat UCL; Non-SuperoLateral, Non-SupLat UCL) locations (LonTranUCL) [Figure 5a]. The rationale for segregating into SupLat UCL and Non-SupLat UCL was that the subthalamic superolateral region is one of most common locations of effective contacts. ${ }^{[3]}$ We individualized a sub-series of 36 patients fitting the most frequent LonTranUCL. Broadly speaking, the most frequent 


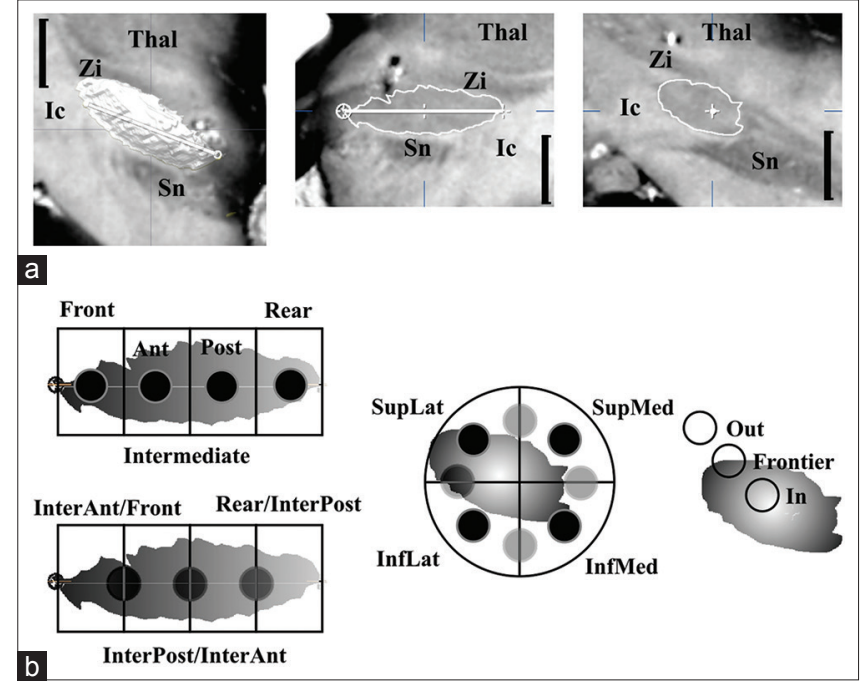

Figure 2: Subdivisions of the anatomic space centered on the subthalamic nucleus (STN). (a) Triplanar 4.7 T MRI of an anatomic specimen (black vertical bar $=5 \mathrm{~mm}$ ): frontal view (left), anterior commissure-posterior commissure aligned, of the STN (3D, white) located below the thalamus (Thal) and zona incerta ( $\mathrm{Zi})$, above the substantia nigra (Sn), and medially to the internal capsule (Ic); longitudinal (intermediate) and transversal (right) sections running through the main axis of STN (white line) and the midpoint (white cross) of the longitudinal axis, respectively. (b) Longitudinal (left) and transversal (intermediate) subdivisions (primary locations, black dots; combined locations, gray dots) and STN membership (right) used to locate the effective contacts (see text for abbreviations)

LonTranUCL was Intermediate or Rear UCL and SupLat UCL. The 53 patients were also regrouped according to STN membership (MembUCL) as In, Out, In-Out, and Frontier MembUCL [Figure 5a]. From the sub-series of 36 patients fitting the most frequent LongTranUCL, we selected 25 patients fitting the most frequent global longitudinal and transversal locations and STN membership (GlobalUCL). Details of the LonTranUC, MembUCL, and GlobalUCL groups of contact pair-ups can be found in the supplementary material [Table 3S].

Balance of contact pair-up (BCPU) was defined as symmetric or asymmetric regardless of laterality (R-L BCPU was not differentiated from L-R BCPU), and was determined for longitudinal, transversal, and STN membership aspects [Figure 5b and Table 4S]. The distribution of BCPU for the 53 patients was simplified and fell into 6 raw conditions [Tables 3 and 5S] that were further pooled into BCPU-asymmetric (17 patients), BCPU-sym-Rear-SupLat-Out (most frequent symmetric condition, 15 patients) and BCPU-sym-other (21 patients). Details of longitudinal, transversal, and STN membership BCPU can be found in the supplementary material.

We studied the left or right hemisphere-wise laterality of most frequent contact pair-ups (MFCP) regardless of either symmetric or asymmetric BCPU [Figure $5 \mathrm{c}$ and $4 \mathrm{c}$; Table 6S]: First, only rear-longitudinal MFCP, named 1-MFCP; second, l-MFCP and SupLat-transversal

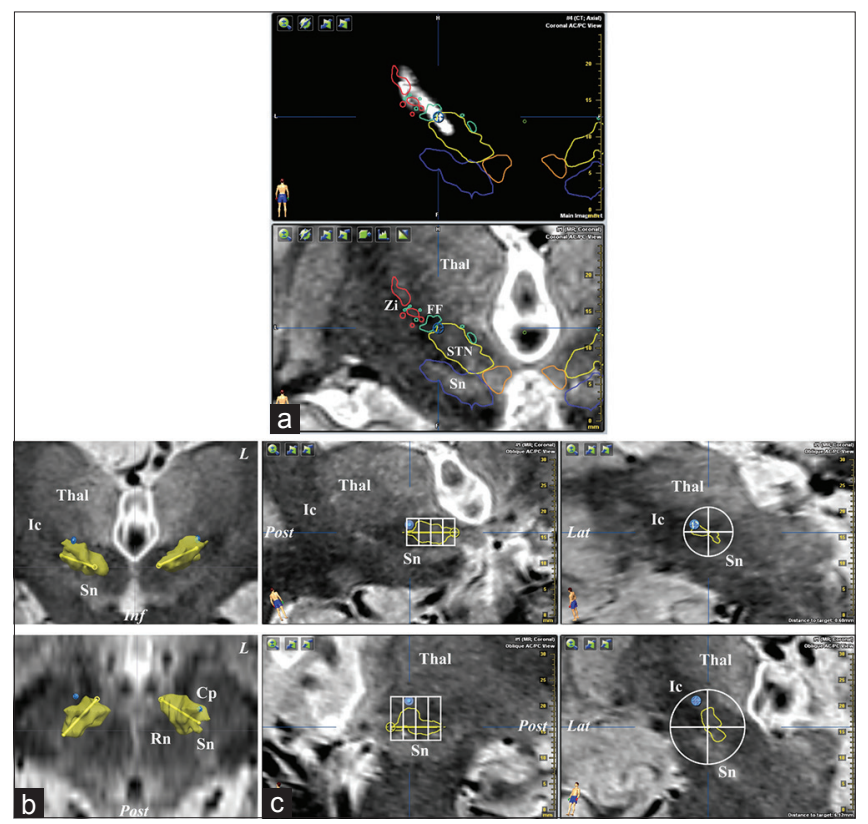

Figure 3: Example (patient \#53, see Table 3) of effective contact location used at I-year post-surgery (I.5 T MRI). (a) Coronal CT-scan (top) and MRI (bottom) slices (perpendicular to anterior commissure-posterior commissure line; light-green dot) running through the effective contact (blue circle; contact I) of the left electrode (white artefact); co-registered; showing the position of the contact at the superior and lateral boundary of the subthalamic nucleus (STN).Thalamus (Thal), zona incerta (Zi), substantia nigra (Sn), and fields of Forel (FF) are shown. (b) Frontal (top; inferior, Inf) and superior (bottom; posterior, Post) views (left, L) of the right and left subthalamic nucleus (yellow): main axis of the nucleus (yellow line) and the effective contacts (blue dots) are shown; Thalamus (Thal), zona incerta ( $\mathrm{Zi})$, substantia nigra ( $\mathrm{Sn}$ ), and internal capsule (Ic). (c) Reconstructed images (left hemisphere, top row; right hemisphere, bottom row) along the main axis of the STN (left column; posterior, Post) and perpendicular to the axis (right column; lateral, Lat) showing contact locations according to longitudinal and transversal subdivisions (white grid) and STN membership (white circle grid): left contact, Rear longitudinal position, SupLat transversal position, and Frontier STN membership; right contact, InterAnt position, SupLat transversal position, and Out STN membership

MFCP, named 2-MFCP; third, 2-MFCP and out-STN-membership MFCP, named 3-MFCP.

\section{Data analysis}

Statistical analysis was performed using Stata software version 13 (StataCorp, College Station, TX). Data were presented as mean \pm standard deviation (SD) or median (interquartile range) for continuous data and as number of patients and associated percentages for categorical parameters. Comparisons between independent groups were analyzed using the Chi-squared test or Fisher's exact test for categorical variables followed, when appropriate, by Marascuillo's procedure, and analysis of variance (ANOVA) or Kruskal-Wallis test for quantitative variables, with normality verified by the Shapiro-Wilk test and homoscedasticity verified by the Bartlett test. When appropriate, post-hoc multiple comparisons tests were proposed (Tukey-Kramer 


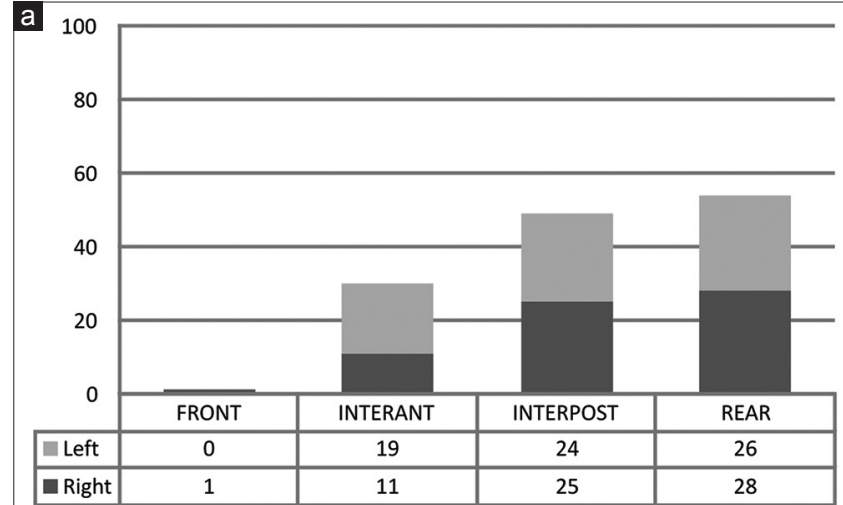

b

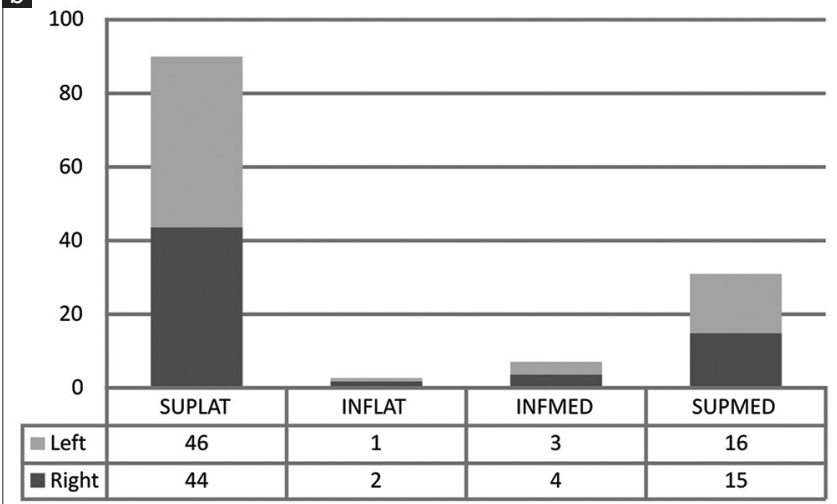

C

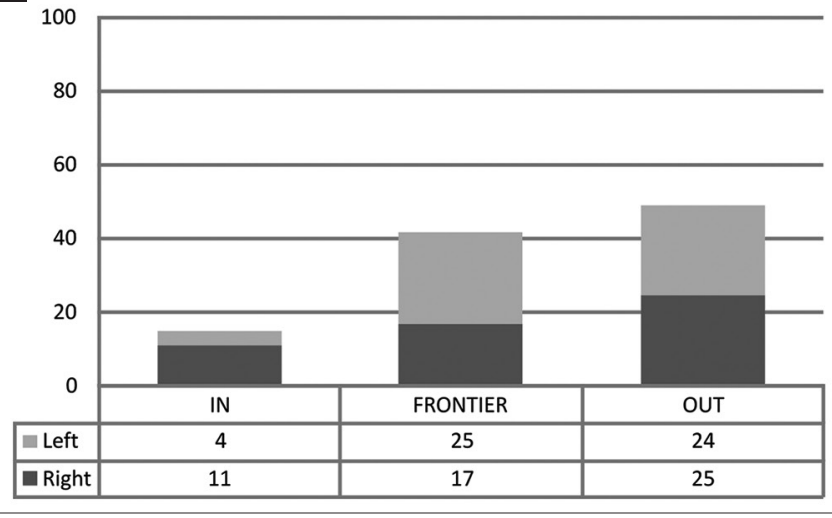

Figure 4: Overall contact locations of the 53 patients according to longitudinal (a) and transversal (b) positions and STN membership (c); sums $>53$ for the right-plus-left contacts result from multiple attributions of contacts overlapping different locations (see text)

after ANOVA and Dunn for Kruskal-Wallis). Non-parametric tests were often preferred due to sample size. For paired comparisons, a paired $t$-test or Wilcoxon test was used for quantitative data and a Stuart-Maxwell test for qualitative parameters. All tests were two-sided, with a type-I error set at $\alpha=0.05$, without mathematical correction. ${ }^{[29]}$

\section{RESULTS}

We did not find differences in UPDRS III motor score, voltage, age, or gender according to UCL

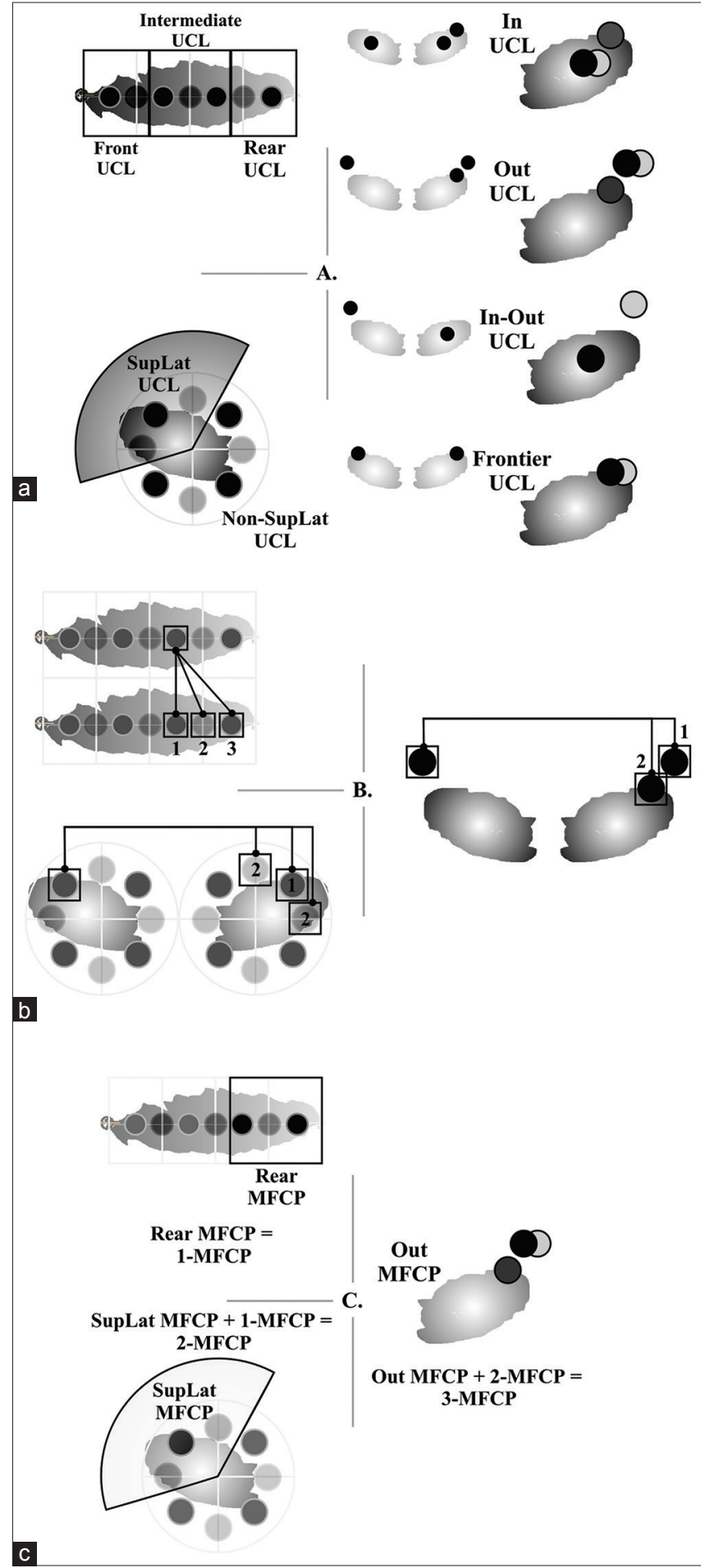

Figure 5: The three methods of contact location according to longitudinal location, transversal location and STN membership: (a) Unified Contact Location (UCL); (b) Balance of Contact Pair-up (BCPU); (c) Most Frequent Contact Pair-up (MFCP)

[Tables 7S and 8S]; whereas mean LED dose at l-year was higher for MembUCL_Out patients than other MembUCL patients $(P=0.03 ; 51$ patients; Table 7S], i.e., $1075 \mathrm{mg}$ [800-1750] for MembUCL_Out vs $800 \mathrm{mg}$ [675-1400] for MembUCL_Frontier, $66 \overline{3} \mathrm{mg}$ 
Table 3: Conditions of balance of balance of contact pair-up of the 53 patients, according to longitudinal and transversal location and STN membership

\begin{tabular}{|c|c|c|c|c|c|c|c|c|c|c|c|c|c|}
\hline \multicolumn{2}{|c|}{ BCPU condition } & \multicolumn{3}{|c|}{ Longitudinal } & \multirow{2}{*}{$\begin{array}{l}\text { Logical } \\
\text { operation }\end{array}$} & \multicolumn{3}{|c|}{ Transversal } & \multirow{2}{*}{$\begin{array}{l}\text { Logical } \\
\text { operation }\end{array}$} & \multicolumn{3}{|c|}{ STN membership } & \multirow[t]{2}{*}{ Patients } \\
\hline Raw & Grouped & Rear & Not-rear & Asymmetric & & SupLat & Not-SupLat & Asymmetric & & Out & Not-out & Asymmetric & \\
\hline BCPUO & Asymmetric & & & Yes & Or & & & Yes & Or & & & Yes & 17 \\
\hline BCPU1 & $\begin{array}{l}\text { Symmetric-rear- } \\
\text { supLat-out }\end{array}$ & Yes & & & And & Yes & & & And & Yes & & & 15 \\
\hline BCPU2 & Symmetric-other & Yes & & & & Yes & & & & & Yes & & 8 \\
\hline BCPU3 & & Yes & & & & & Yes & & & Yes & & & 4 \\
\hline BCPU4 & & & Yes & & & Yes & & & & Yes & & & 3 \\
\hline BCPU5 & & & Yes & & & Yes & & & & & Yes & & 6 \\
\hline
\end{tabular}

BCPU: Balance of contact pair-up, STN: Subthalamic nucleus

[450-1100] for MembUCL In, and $500 \mathrm{mg}$ [450-850] for MembUCL_In-Out. UP̄DRS III speech sub-score worsening (1-year versus preop) was more frequent for MembUCL_Out patients with medication $(P=0.005$, most frequent patients, $n=33$; option $\mathrm{B}$, sensitive to worsening; Table 8S).

We did not find differences in UPDRS III motor score, voltage, age, and gender according to BCPU [Tables 9S and 10S]; whereas mean preoperative LED dose was higher for BCPU-sym-Rear-SupLat-Out patients than other BCPU patients ( $P=0.03$; 53 patients; Table $9 \mathrm{~S})$, at $1438 \mathrm{mg}$ [1175-1650] for BCPU-sym-Rear-SupLat-Out vs $1125 \mathrm{mg}$ [975-1300] for BCPU-sym-other, and $1030 \mathrm{mg}$ [650-1550] for BCPU-asymmetric. BCPU-asymmetric patients had less speech sub-score worsening, with medication, with either UPDRS III (at l-year; $P<0.05$, $n=46$; option A, less sensitive to worsening; versus BCPU-sym-Rear-SupLat-Out and BCPU-sym-other) or UPDRS II ( 1 year vs preop; $P<0.05, n=48$; option B, sensitive to worsening; vs the others) [Table 10S].

We did not find differences in voltage and age according to MFCP [Tables $11 \mathrm{~S}$ and $12 \mathrm{~S}$ ], whereas mean preoperative LED dose of right contact was higher for 1-MFCP (rear MFCP) patients than other patients, at $1306 \mathrm{mg}$ [980-1550] for 1-MFCP (rear MFCP) vs 975 mg [650-1250] ( $P=0.03$; 53 patients; Table 11S). We also found that females presented more 3-MFCP (rear-SupLat-out MFCP), either right-wise $(P=0.03$; $n=53)$ or left-wise $(P=0.05, n=53)$ [Table 11S]. The left contact of MFCP was associated with more frequent speech worsening in different conditions [Table 12S]: (i) 1-MFCP (rear) patients, l year vs. preop (option A, less sensitive to worsening), UPDRS II speech sub-score worsening with medication $(P=0.01, n=48)$, and UPDRS III speech sub-score without medication ( $P=0.04, n=53)$; (ii) 2-MFCP (rear-SupLat) patients, 1 year vs. preop, UPDRS II speech sub-score worsening with medication (option B, sensitive to worsening; $P=0.02, n=48)$, and at 1 year, UPDRS III speech sub-score worsening without medication (option A, less sensitive to worsening; $P=0.02, n=48$ ); (iii) 3 -MFCP (rear-SupLat-out) patients, at 1 year, UPDRS III speech sub-score worsening with medication (option A, less sensitive to worsening; $P=0.05, n=46)$. The right contact of 1-MFCP (rear) patients was also associated with more frequent speech worsening, 1 year vs. preop, UPDRS II speech sub-score with medication (option B, sensitive to worsening; $P=0.048, n=48$ ). The right contact of 2-MFCP (rear-SupLat) patients was associated with more frequent UPDRS II freezing sub-score worsening, l year vs. preop, without medication (option A, less sensitive to worsening; $P=0.03, n=48)$.

The full results are summarized in Figure 6.

\section{DISCUSSION}

Our results show that the precise location of effective contacts within the subthalamic region, regardless of the method used for location analysis, i.e. UCL, individual balance of contact pair-ups, or individual hemisphere-wise most frequent contact pair-up, does not explain the degree of motor improvement (UPDRS III). Consequently, the only key factor would be location within the subthalamic region, provided the contact is located within, at the frontier, or above the STN. These results are consistent with other studies reporting effective contact location, using different methods, at different locations in the subthalamic region (see Supplementary material) or even as far as the internal capsule. ${ }^{[37]}$ Nevertheless, high percentage drops in UPDRS III motor score have been reported when the contact is located within the STN, whether associative or sensorimotor, compared with the zona incerta, ${ }^{[37]}$ suggesting that STN DBS should be more efficient on motor symptoms, at least those evaluated by UPDRS. ${ }^{[1,34]}$ The importance of involvement of the sensorimotor component of the $\mathrm{STN}^{[32,38]}$ within the volume of electric stimulation commonly estimated as a sphere of $2-5 \mathrm{~mm}$ radius $^{[36]}$ is not challenged by our results $(\approx 86 \%$ of contacts here were located at the boundary 


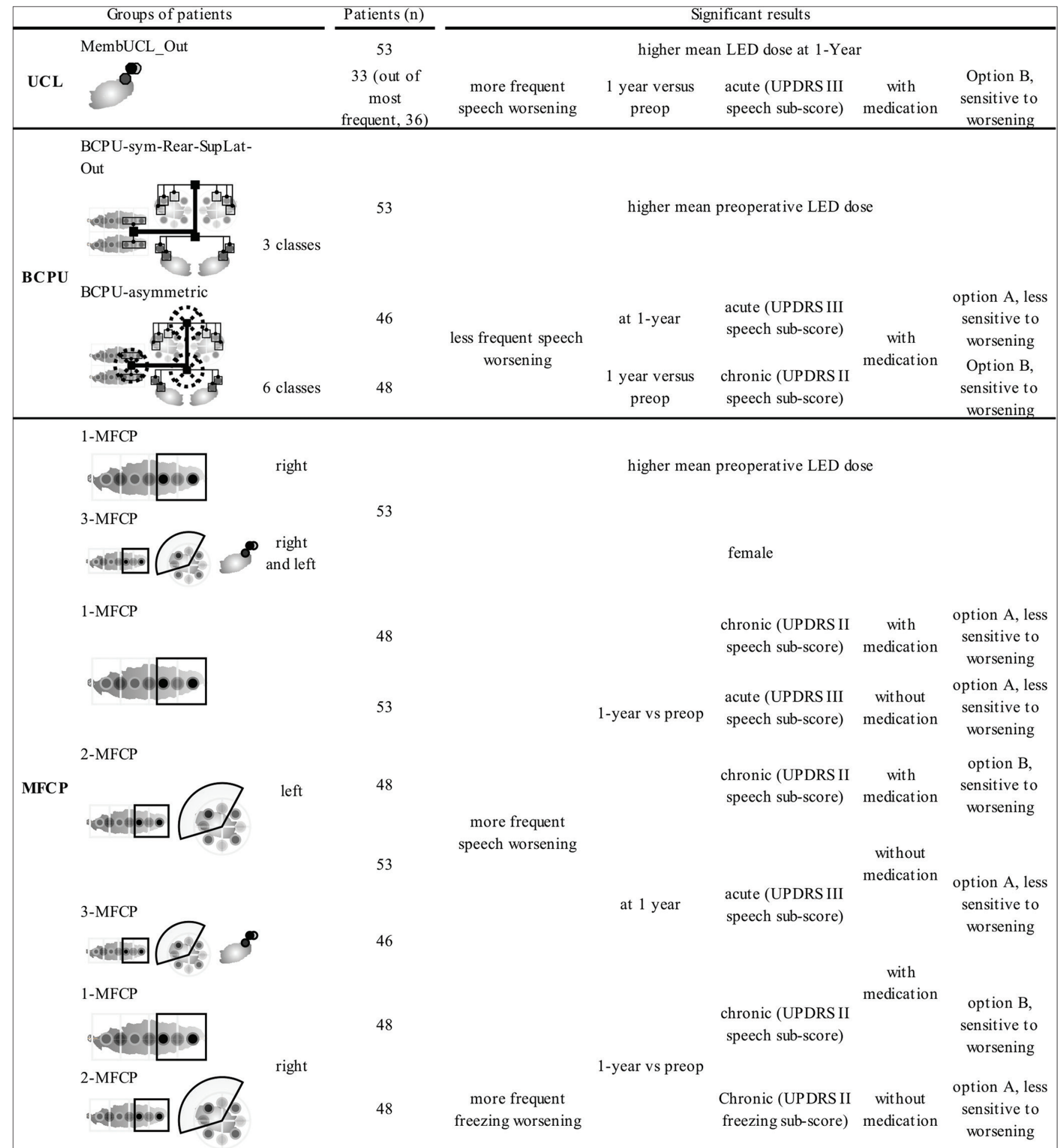

Figure 6: Synthesis of results (see text for details)

or outside the STN) nor the results of Welter et al. ${ }^{[37]}$ (contacts were within the associative and sensorimotor parts), as it is very likely that corticosubcorticothalamic loops are modulated directly by contacts within or at the boundary of the STN or indirectly by outside contacts placed on corticosubthalamic white matter fibers crossing the zona incerta below the thalamus. ${ }^{[19]}$ Our results add support to the functional segregation proposed by Yelnik et al. ${ }^{[38]}$ because most contacts were located superiorly, posteriorly, and laterally relative to STN. Interestingly, we observed that out-STN patients, whether with right or left locations unified (MembUCL Out patients) or symmetric Rear-SupLat-Out balance pair-ups (BCPU-sym-Rear-SupLat-Out patients) have higher 
postoperative LED at 1 year than patients with other contact locations. A tentative explanation would be that electric modulation does not activate dopaminergic release as much as direct STN stimulation, although we cannot rule out an influence of disease severity, as suggested by the increase of UPDRS III baseline (dopa off-stim off) in our series, and our relatively elderly population of mean age 60.9 whereas recent series studied younger patients. ${ }^{[30,37]}$

We also found that contacts located outside the STN seemed associated with more frequent speech worsening, regardless of the hemisphere and balance contact pair-up (acute test with medication versus preoperative scores). It appears as though electric stimulation plus dopamine functionally disrupts speech circuitry, specifically categorical fluency. ${ }^{[17]}$ Speech intelligibility is also lower when using acute high-voltage STN stimulation compared to low-voltage protocols, ${ }^{[34]}$ possibly because high voltage modulates circuits located outside STN. We have also found that speech deterioration is reduced, with medication, when the right and left contacts are not symmetrical, suggesting that symmetric stimulation conditions more heavily deteriorate speech controls. We found that the left contact (only 2 left-handed patients out of 53) seems particularly involved in this stimuli-induced adverse effect, confirming published results by Tripoliti et $a l .{ }^{[33]}$ and Sjöberg et al. ${ }^{[31]}$ Speech worsening also seems to be influenced by anteroposterior and mediolateral location because we observed more dysarthria for posterior and lateral locations; however, medial and anterior contact positions appear to be equally involved. ${ }^{[33,34]}$ This variability could be related to the patient studied and the method of contact location analysis used.

In regards to freezing worsening, we observed that regardless of STN membership, patients with the right contact located posteriorly and laterally were more prone to worsening. We hypothesize that fibers ascending from the pedunculopontine nucleus (PPN) toward the substantia nigra compacta, STN, pallidum, and thalamus ${ }^{[25,26]}$ and fibers projecting from the substantia nigra reticulata and the internal globus pallidus ${ }^{[26]}$ could be influenced by electric field. More data are needed to understand the laterality of effects. Clinical DBS studies have also reported that unilateral PPN stimulation contralateral to the most severely-affected side of the body seems to improve falls ${ }^{[20]}$ and modulate contralateral or bilateral inferior limb muscular activity during the steady state of gait. ${ }^{[4]}$ Dorsal STN stimulation modulates gait velocity assessed during acute tests, using cerebellar loops. ${ }^{[14]}$ Other lateralized differentiated effects have been reported such as the reduction of motor disability, axial scores and levodopa daily dose, lower if the right contact is more anterior ${ }^{[37]}$ and left STN DBS seems to lead to more improved mood. ${ }^{[5]}$

\section{CONCLUSIONS}

Right-left contact pair-up could be an important factor for optimization of DBS electrode targeting and electric stimulation parameter, in severe Parkinson's disease, and for efforts to gain a sharper understanding of the precise mechanisms of effects. Neurologists should aim to position right and left contacts asymmetrically to the STN landmark to minimize speech worsening. In particular, the left contact should not be in posterior, superior, and lateral position. The data reported here could be used for surgical targeting and proposed to neurologists as postoperative electrical settings if contacts are remotely selectable and anatomical location is known.

\section{Acknowledgments}

The authors thank Dr V. Mendes and Dr L. Ouchchane for their constructive comments during the very first phase of research project.

Financial support and sponsorship

Nil.

Conflicts of interest

There are no conflicts of interest.

\section{REFERENCES}

I. Benabid AL, Chabardes S, Mitrofanis J, Pollak P. Deep brain stimulation of the subthalamic nucleus for the treatment of Parkinson's disease. Lancet Neurol 2009;8:67-8I.

2. Boertien T, Zrinzo L, Kahan J, Jahanshahi M, Hariz M, Mancini L, et al. Functional imaging of subthalamic nucleus deep brain stimulation in Parkinson's disease. Mov Disord 20I I; Available: http://www.ncbi.nlm.nih. gov/pubmed/21674623. [Last accessed on 20II July I5].

3. Caire F, Derost P, Coste J, Bonny JM, Durif F, Frenoux E, et al. Subthalamic deep brain stimulation for severe idiopathic Parkinson's disease. Location study of the effective contacts. Neurochirurgie 2006;52:15-25.

4. Caliandro P, Insola A, Scarnati E, Padua L, Russo G, Granieri E, et al. Effects of unilateral pedunculopontine stimulation on electromyographic activation patterns during gait in individual patients with Parkinson's disease. J Neural Transm 201 I; I 18:1477-86.

5. Campbell MC, Black KJ, Weaver PM, Lugar HM, Videen TO, Tabbal SD, et al. Mood response to deep brain stimulation of the subthalamic nucleus in Parkinson's disease. J Neuropsychiatry Clin Neurosci 2012;24:28-36.

6. Coste J, Ouchchane L, Sarry L, Derost P, Durif F, Gabrillargues J, et al. New electrophysiological mapping combined with MRI in parkinsonian's subthalamic region. Eur J Neurosci 2009;29:1627-33.

7. Falowski SM, Sharan A, Reyes BA, Sikkema C, Szot P, Van Bockstaele EJ. An evaluation of neuroplasticity and behavior after deep brain stimulation of the nucleus accumbens in an animal model of depression. Neurosurgery 2011;69:1281-90.

8. Fasano A, Daniele A, Albanese A. Treatment of motor and non-motor features of Parkinson's disease with deep brain stimulation. Lancet Neurol 2012; I I:429-42.

9. Fenoy AJ, Goetz L, Chabardès S, Xia Y. Deep brain stimulation: Are astrocytes a key driver behind the scene? CNS Neurosci Ther 2014;20:191-20I.

10. Guehl D, Vital A, Cuny E, Spampinato U, Rougier A, Bioulac B, et al. Postmortem proof of effectiveness of zona incerta stimulation in Parkinson disease. Neurology 2008;70:1489-90.

II. Hariz M. Deep brain stimulation: New techniques. Parkinsonism Relat Disord 20I4;20(SuppI I):SI92-6. 
12. Haynes WI, Haber SN. The organization of prefrontal-subthalamic inputs in primates provides an anatomical substrate for both functional specificity and integration: Implications for Basal Ganglia models and deep brain stimulation. J Neurosci 2013;33:4804-14.

13. Hemm S, Coste J, Gabrillargues J, Ouchchane L, Sarry L, Caire F, et al. Contact position analysis of deep brain stimulation electrodes on post-operative CT images. Acta Neurochir 2009;151:823-9.

14. Hill KK, Campbell MC, McNeely ME, Karimi M, Ushe M, Tabbal SD, et al. Cerebral blood flow responses to dorsal and ventral STN DBS correlate with gait and balance responses in Parkinson's disease. Exp Neurol 2013;241:105-12.

15. Hilliard JD, Frysinger RC, Elias WJ. Effective subthalamic nucleus deep brain stimulation sites may differ for tremor, bradykinesia and gait disturbances in Parkinson's disease. Stereotact Funct Neurosurg 201 I;89:357-64.

16. Karlsson F, Olofsson K, Blomstedt P, Linder J, van Doorn J. Pitch variability in patients with Parkinson's disease: Effects of deep brain stimulation of caudal zona incerta and subthalamic nucleus. J Speech Lang Hear Res 2013;56:150-8.

17. Lalys F, Haegelen C, Mehri M, Drapier S,Vérin M, Jannin P.Anatomo-clinical atlases correlate clinical data and electrode contact coordinates: Application to subthalamic deep brain stimulation. J Neurosci Methods 2013;2। 2:297-307.

18. Lemaire JJ, Coste J, Ouchchane L, Caire F, Nuti C, Derost P, et al. Brain mapping in stereotactic surgery: A brief overview from the probabilistic targeting to the patient-based anatomic mapping. Neuroimage 2007;37(Suppl I):S109-15.

19. Lemaire J-J, Cosnard G, Sakka L, Nuti C, Gradkowski W, Mori S, et al. White matter anatomy of the human deep brain revisited with high resolution DTI fibre tracking. Neurochirurgie 201 1;57:52-67.

20. Moro E, Hamani C, Poon YY, Al-Khairallah T, Dostrovsky JO, Hutchison WD, et al. Unilateral pedunculopontine stimulation improves falls in Parkinson's disease. Brain 2009;133:215-24.

21. Nieuwenhuys R, Voogd J, Huijzen C. The human central nervous system: A synopsis and atlas. Berlin: Springer-Verlag; 1979.

22. Obeso JA, Rodríguez-Oroz MC, Benitez-Temino B, Blesa FJ, Guridi J, Marin $\mathrm{C}$, et al. Functional organization of the basal ganglia: Therapeutic implications for Parkinson's disease. Mov Disord 2008;23(Suppl 3):S548-59.

23. Okun MS. Deep-brain stimulation for Parkinson's disease. N Engl J Med 2012;367:1529-38

24. Okun MS. Deep-brain stimulation for Parkinson's disease. N Engl J Med 2013;368:483-4

25. Parent A, Côté PY, Lavoie B. Chemical anatomy of primate basal ganglia. Prog Neurobiol 1995;46:131-97.
26. Parent A, Hazrati LN. Functional anatomy of the basal ganglia. I. The cortico-basal ganglia-thalamo-cortical loop. Brain Res Brain Res Rev 1995;20:91-127.

27. Plaha P, Ben-Shlomo Y, Patel NK, Gill SS. Stimulation of the caudal zona incerta is superior to stimulation of the subthalamic nucleus in improving contralateral parkinsonism. Brain 2006; 129: 1732-47.

28. Pötter-Nerger M, Volkmann J. Deep brain stimulation for gait and postural symptoms in Parkinson's disease. Mov Disord 2013;28:1609-15.

29. Rothman KJ. No adjustments are needed for multiple comparisons. Epidemiology 1990; I:43-6.

30. Schuepbach WMM, Rau J, Knudsen K, Volkmann J, Krack P, Timmermann L, et al. Neurostimulation for Parkinson's disease with early motor complications. N Engl J Med 2013;368:610-22.

3I. Sjöberg RL, Lidman E, Häggström B, Hariz MI, Linder J, Fredricks A, et al. Verbal fluency in patients receiving bilateral versus left-sided deep brain stimulation of the subthalamic nucleus for Parkinson's disease. J Int Neuropsychol Soc 2012;18:606-II.

32. Temel Y, Blokland A, Steinbusch HW, Visser-Vandewalle V. The functional role of the subthalamic nucleus in cognitive and limbic circuits. Prog Neurobiol 2005;76:393-413.

33. Tripoliti E, Zrinzo L, Martinez-Torres I, Frost E, Pinto S, Foltynie T, et al. Effects of subthalamic stimulation on speech of consecutive patients with Parkinson disease. Neurology 201 1;76:80-6.

34. Tripoliti E, Zrinzo L, Martinez-Torres I, Tisch S, Frost E, Borrell E, et al. Effects of contact location and voltage amplitude on speech and movement in bilateral subthalamic nucleus deep brain stimulation. Mov Disord 2008;23:2377-83.

35. Voges J, Volkmann J, Allert N, Lehrke R, Koulousakis A, Freund HJ, et al. Bilateral high-frequency stimulation in the subthalamic nucleus for the treatment of Parkinson disease: Correlation of therapeutic effect with anatomical electrode position. J Neurosurg 2002;96:269-79.

36. Volkmann J, Moro E, Pahwa R. Basic algorithms for the programming of deep brain stimulation in Parkinson's disease. Mov Disord 2006;21:S284-9.

37. Welter ML, Schüpbach M, Czernecki V, Karachi C, Fernandez-Vidal S, Golmard JL, et al. Optimal target localization for subthalamic stimulation in patients with Parkinson disease. Neurology 2014;82:1352-61.

38. Yelnik J, Bardinet E, Dormont D, Malandain G, Ourselin S, Tandé D, et al. A three-dimensional, histological and deformable atlas of the human basal ganglia. I. Atlas construction based on immunohistochemical and MRI data. Neuroimage 2007;34:618-38.

39. Zonenshayn M, Sterio D, Kelly PJ, Rezai AR, Beric A. Location of the active contact within the subthalamic nucleus (STN) in the treatment of idiopathic Parkinson's disease. Surg Neurol 2004;62:216-25. 


\section{SUPPLEMENTARY MATERIAL 2}

Subthalamus deep brain stimulation in parkinson's disease: Accounting for the bilaterality of contacts

Table 1S: Assessments of speech and freezing: (1) Speech, 1-year vs preoperative values of UPDRS II speech subscore based on spontaneous fluctuations (or chronic condition), with and without medication, and of UPDRS III speech sub-score in acute condition with and without medication; (2) Speech at 1 year, stimON vs stimOFF, with and without medication; (3) Freezing, 1-year vs preoperative values of the UPDRS II freezing sub-score based on spontaneous fluctuations when walking (or chronic condition) with and without medication

\begin{tabular}{|c|c|c|c|c|c|}
\hline Assessment & Period & Type & & Condition & Abbreviation \\
\hline \multirow[t]{2}{*}{ Speech } & $\begin{array}{l}\text { 1-year vs } \\
\text { preoperative } \\
\text { values }\end{array}$ & $\begin{array}{l}\text { UPDRS II speech } \\
\text { sub-score based on } \\
\text { spontaneous fluctuations } \\
\text { (or chronic condition) }\end{array}$ & $\begin{array}{l}\text { with medication } \\
\text { without medication }\end{array}$ & $\begin{array}{l}\text { MedON_Stim0N1y_vsPreop } \\
\text { MedOFF_Stim0N1y_vsPreop }\end{array}$ & $\begin{array}{l}\text { SpeeChro_MedON_1yvsPreop } \\
\text { SpeeChro_MedOFF_1yvsPreop }\end{array}$ \\
\hline & 1 year & $\begin{array}{l}\text { UPDRS III speech sub- } \\
\text { score in acute condition }\end{array}$ & $\begin{array}{l}\text { with medication } \\
\text { without medication } \\
\text { with medication } \\
\text { without medication }\end{array}$ & $\begin{array}{l}\text { MedON_Stim0N1year - vsPreop } \\
\text { MedOFF_Stim0N1year - vsPreop } \\
\text { MedON_Stim0N1year_vsStimOFF1year } \\
\text { MedOFF_Stim0N1year_vsStim0FF1year }\end{array}$ & $\begin{array}{l}\text { SpeeAcc_MedON_1yvsPreop } \\
\text { SpeeAcc_MedOFF_1yvsPreop } \\
\text { SpeeAcc_Med0N_1y } \\
\text { SpeeAcc_MedOFF_1y }\end{array}$ \\
\hline Freezing & $\begin{array}{l}\text { 1-year vs } \\
\text { preoperative } \\
\text { values }\end{array}$ & $\begin{array}{l}\text { UPDRS II freezing } \\
\text { sub-score based on } \\
\text { spontaneous fluctuations } \\
\text { when walking (or } \\
\text { chronic condition) }\end{array}$ & $\begin{array}{l}\text { with medication } \\
\text { without medication }\end{array}$ & $\begin{array}{l}\text { MedON_Stim0N1year_vsPreop } \\
\text { MedOFF_Stim0N1year_vsPreop }\end{array}$ & $\begin{array}{l}\text { FreeChro_MedON_1yvsPreop } \\
\text { FreeChro_MedOFF_1yvsPreop }\end{array}$ \\
\hline
\end{tabular}

Table 2S: Individual right and left effective contact locations of the 53 patients according to longitudinal and transversal positions and STN membership

\begin{tabular}{|c|c|c|c|c|c|c|}
\hline \multirow[t]{2}{*}{ Patient } & \multicolumn{3}{|c|}{ Left hemisphere } & \multicolumn{3}{|c|}{ Right hemisphere } \\
\hline & Longitudinal position & Transversal position & STN membership & Longitudinal position & Transversal position & STN membership \\
\hline 1 & REAR/INTERPOST & SUPLAT & FRONTIER & REAR & SUPLAT/SUPMED & OUT \\
\hline 2 & INTERPOST/INTERANT & SUPLAT/SUPMED & FRONTIER & REAR & SUPLAT/SUPMED & FRONTIER \\
\hline 3 & INTERPOST/INTERANT & SUPLAT & OUT & INTERPOST & SUPLAT & IN \\
\hline 4 & INTERANT & SUPLAT/SUPMED & IN & INTERPOST/INTERANT & SUPLAT & FRONTIER \\
\hline 5 & INTERPOST/INTERANT & SUPLAT & FRONTIER & REAR & SUPLAT & OUT \\
\hline 6 & REAR & SUPLAT & FRONTIER & REAR/INTERPOST & INFMED/INFLAT & IN \\
\hline 7 & INTERANT & SUPMED & OUT & INTERPOST/INTERANT & SUPLAT & FRONTIER \\
\hline 8 & REAR & SUPLAT & OUT & REAR & SUPMED & OUT \\
\hline 9 & INTERPOST & SUPLAT/SUPMED & OUT & REAR & SUPMED & OUT \\
\hline 10 & INTERANT & SUPLAT & FRONTIER & INTERPOST & SUPLAT & OUT \\
\hline 11 & INTERPOST & SUPLAT & OUT & INTERANT/FRONT & SUPMED & IN \\
\hline 12 & REAR/INTERPOST & SUPMED & OUT & REAR/INTERPOST & SUPLAT/SUPMED & IN \\
\hline 13 & REAR & SUPMED/INFMED & OUT & INTERPOST & INFMED & FRONTIER \\
\hline 14 & INTERPOST & SUPLAT & OUT & INTERPOST/INTERANT & SUPLAT & IN \\
\hline 15 & REAR & SUPLAT/SUPMED & OUT & INTERPOST & SUPMED & OUT \\
\hline 16 & INTERPOST/INTERANT & SUPLAT/SUPMED & OUT & INTERANT & SUPLAT & OUT \\
\hline 17 & INTERPOST & SUPLAT/SUPMED & OUT & INTERPOST & SUPLAT/SUPMED & FRONTIER \\
\hline 18 & REAR & SUPLAT & FRONTIER & INTERPOST & SUPLAT & FRONTIER \\
\hline 19 & REAR & SUPLAT & FRONTIER & REAR & SUPLAT & FRONTIER \\
\hline 20 & INTERPOST & SUPLAT & FRONTIER & INTERPOST & SUPLAT & OUT \\
\hline 21 & REAR & SUPLAT & OUT & REAR & INFLAT & IN \\
\hline 22 & INTERPOST & SUPLAT & FRONTIER & INTERANT & SUPLAT & OUT \\
\hline 23 & INTERPOST/INTERANT & SUPLAT & FRONTIER & REAR/INTERPOST & SUPLAT & OUT \\
\hline 24 & INTERPOST/INTERANT & SUPLAT & FRONTIER & INTERPOST/INTERANT & SUPLAT & FRONTIER \\
\hline
\end{tabular}


Table 2S: Contd...

\begin{tabular}{|c|c|c|c|c|c|c|}
\hline \multirow[t]{2}{*}{ Patient } & \multicolumn{3}{|c|}{ Left hemisphere } & \multicolumn{3}{|c|}{ Right hemisphere } \\
\hline & Longitudinal position & Transversal position & STN membership & Longitudinal position & Transversal position & STN membership \\
\hline 25 & REAR & SUPLAT & OUT & INTERPOST & SUPLAT & FRONTIER \\
\hline 26 & REAR & SUPLAT & OUT & INTERPOST & SUPLAT & OUT \\
\hline 27 & REAR & SUPLAT & OUT & REAR & SUPLAT & OUT \\
\hline 28 & REAR & SUPLAT & OUT & REAR & SUPMED & OUT \\
\hline 29 & REAR/INTERPOST & SUPLAT & FRONTIER & REAR & SUPLAT/SUPMED & OUT \\
\hline 30 & INTERANT & $\begin{array}{l}\text { SUPLAT/SUPMED/ } \\
\text { INFMED/INFLAT }\end{array}$ & IN & INTERANT & SUPLAT & FRONTIER \\
\hline 31 & REAR & SUPLAT/SUPMED & FRONTIER & REAR & INFMED & OUT \\
\hline 32 & INTERANT & SUPLAT & FRONTIER & INTERPOST/INTERANT & SUPLAT & FRONTIER \\
\hline 33 & REAR/INTERPOST & SUPLAT & FRONTIER & INTERPOST & SUPLAT & IN \\
\hline 34 & REAR & SUPLAT & OUT & REAR/INTERPOST & SUPLAT & OUT \\
\hline 35 & INTERANT & SUPLAT & FRONTIER & REAR/INTERPOST & SUPLAT/SUPMED & IN \\
\hline 36 & INTERANT & SUPMED & FRONTIER & REAR & SUPLAT & OUT \\
\hline 37 & REAR/INTERPOST & SUPLAT & OUT & REAR & SUPLAT & FRONTIER \\
\hline 38 & INTERPOST/INTERANT & SUPLAT & IN & REAR & SUPLAT & FRONTIER \\
\hline 39 & INTERPOST & SUPLAT & OUT & REAR & SUPLAT & OUT \\
\hline 40 & INTERANT & SUPLAT/SUPMED & FRONTIER & INTERPOST & SUPLAT & FRONTIER \\
\hline 41 & INTERANT & SUPLAT & FRONTIER & REAR & SUPLAT & OUT \\
\hline 42 & REAR & SUPMED & OUT & REAR & SUPLAT & OUT \\
\hline 43 & REAR & SUPLAT & OUT & REAR/INTERPOST & SUPLAT & OUT \\
\hline 44 & REAR & SUPLAT & FRONTIER & REAR & SUPLAT/SUPMED & IN \\
\hline 45 & REAR/INTERPOST & SUPLAT & FRONTIER & INTERPOST & SUPMED/INFMED & IN \\
\hline 46 & REAR & SUPLAT & OUT & REAR & SUPLAT & FRONTIER \\
\hline 47 & INTERPOST/INTERANT & INFMED & IN & REAR & SUPLAT & IN \\
\hline 48 & REAR & SUPLAT & FRONTIER & INTERPOST & SUPLAT & FRONTIER \\
\hline 49 & INTERPOST/INTERANT & SUPLAT/SUPMED & FRONTIER & REAR & SUPLAT/SUPMED & OUT \\
\hline 50 & INTERPOST/INTERANT & SUPLAT & FRONTIER & INTERPOST/INTERANT & SUPLAT/SUPMED & FRONTIER \\
\hline 51 & REAR & SUPMED & OUT & REAR & SUPLAT & OUT \\
\hline 52 & REAR & SUPLAT & OUT & REAR & SUPLAT & OUT \\
\hline 53 & REAR & SUPLAT & FRONTIER & INTERANT & SUPLAT & OUT \\
\hline
\end{tabular}

Longitudinal positions: Frontal (FRONT), intermediate anterior (INTERANT), intermediate posterior (INTERPOST) and posterior (REAR); transversal positions: superolateral (SUPLAT), Inferolateral (INFLAT), Inferomedial (INFMED) and superomedial (SUPMED); STN membership, within (IN), at the frontier (FRONTIER) or outside (OUT) the STN. (See text for details)

Table 3S: Unified Contact Location (UCL) summarizing right and left contact positions of each patient $(n=53)$ according to the simplified longitudinal (Front, Intermediate and Rear) and transversal (Supero-Lateral and Non-Supero-Lateral) locations and STN membership: 14 (1 to 14) longitudinal and transversal UCLs; 4 STN-membership UCLs (in, Out, Frontier and In-Out) (See text for details)

\begin{tabular}{|c|c|c|c|c|c|c|}
\hline \multirow[t]{2}{*}{ Patient } & \multicolumn{2}{|c|}{ Left hemisphere } & \multicolumn{2}{|c|}{ Right hemisphere } & \multicolumn{2}{|c|}{ UCL } \\
\hline & $\begin{array}{l}\text { Longitudinal } \\
\text { simplification }\end{array}$ & $\begin{array}{l}\text { Transversal } \\
\text { simplification }\end{array}$ & $\begin{array}{l}\text { Longitudinal } \\
\text { simplification }\end{array}$ & $\begin{array}{l}\text { Transversal } \\
\text { simplification }\end{array}$ & LongTrans & Memb \\
\hline 1 & Rear & Superolateral & Rear & Superolateral & 13 & Out \\
\hline 2 & Intermediate & Superolateral & Rear & Superolateral & 5 & Frontier \\
\hline 3 & Intermediate & Superolateral & Intermediate & Superolateral & 3 & In-Out \\
\hline 4 & Intermediate & Superolateral & Intermediate & Superolateral & 3 & $\ln$ \\
\hline 5 & Intermediate & Superolateral & Rear & Superolateral & 5 & Out \\
\hline 6 & Rear & Superolateral & Rear & Non-Superolateral & 12 & $\ln$ \\
\hline 7 & Intermediate & Non-Superolateral & Intermediate & Superolateral & 1 & Out \\
\hline 8 & Rear & Superolateral & Rear & Non-Superolateral & 14 & Out \\
\hline 9 & Intermediate & Superolateral & Rear & Non-Superolateral & 6 & Out \\
\hline
\end{tabular}


Table 3S: Contd...

\begin{tabular}{|c|c|c|c|c|c|c|}
\hline \multirow[t]{2}{*}{ patient } & \multicolumn{2}{|c|}{ Left hemisphere } & \multicolumn{2}{|c|}{ Right hemisphere } & \multicolumn{2}{|c|}{ UCL } \\
\hline & $\begin{array}{l}\text { Longitudinal } \\
\text { simplification }\end{array}$ & $\begin{array}{l}\text { Transversal } \\
\text { simplification }\end{array}$ & $\begin{array}{l}\text { Longitudinal } \\
\text { simplification }\end{array}$ & $\begin{array}{l}\text { Transversal } \\
\text { simplification }\end{array}$ & LongTrans & Memb \\
\hline 10 & Intermediate & Superolateral & Intermediate & Superolateral & 3 & Out \\
\hline 11 & Intermediate & Superolateral & $\begin{array}{l}\text { Front } \\
\text { (InterAnt- } \\
\text { Front) }\end{array}$ & Non-Superolateral & 4 & In-Out \\
\hline 12 & Rear & Non-Superolateral & Rear & Superolateral & 9 & In-Out \\
\hline 13 & Rear & Non-Superolateral & Intermediate & Non-Superolateral & 8 & Out \\
\hline 14 & Intermediate & Superolateral & Intermediate & Superolateral & 3 & In-Out \\
\hline 15 & Rear & Superolateral & Intermediate & Non-Superolateral & 11 & Out \\
\hline 16 & Intermediate & Superolateral & Intermediate & Superolateral & 3 & Out \\
\hline 17 & Intermediate & Superolateral & Intermediate & Superolateral & 3 & Out \\
\hline 18 & Rear & Superolateral & Intermediate & Superolateral & 10 & Frontier \\
\hline 19 & Rear & Superolateral & Rear & Superolateral & 13 & Frontier \\
\hline 20 & Intermediate & Superolateral & Intermediate & Superolateral & 3 & Out \\
\hline 21 & Rear & Superolateral & Rear & Non-Superolateral & 12 & In-Out \\
\hline 22 & Intermediate & Superolateral & Intermediate & Superolateral & 3 & Out \\
\hline 23 & Intermediate & Superolateral & Rear & Superolateral & 5 & Out \\
\hline 24 & Intermediate & Superolateral & Intermediate & Superolateral & 3 & Frontier \\
\hline 25 & Rear & Superolateral & Intermediate & Superolateral & 10 & Out \\
\hline 26 & Rear & Superolateral & Intermediate & Superolateral & 10 & Out \\
\hline 27 & Rear & Superolateral & Rear & Superolateral & 13 & Out \\
\hline 28 & Rear & Superolateral & Rear & Non-Superolateral & 14 & Out \\
\hline 29 & Rear & Superolateral & Rear & Superolateral & 13 & Out \\
\hline 30 & Intermediate & Non-Superolateral & Intermediate & Superolateral & 1 & $\ln$ \\
\hline 31 & Rear & Superolateral & Rear & Non-Superolateral & 14 & Out \\
\hline 32 & Intermediate & Superolateral & Intermediate & Superolateral & 3 & Frontier \\
\hline 33 & Rear & Superolateral & Intermediate & Superolateral & 10 & $\ln$ \\
\hline 34 & Rear & Superolateral & Rear & Superolateral & 13 & Out \\
\hline 35 & Intermediate & Superolateral & Rear & Superolateral & 5 & $\ln$ \\
\hline 36 & Intermediate & Non-Superolateral & Rear & Superolateral & 2 & Out \\
\hline 37 & Rear & Superolateral & Rear & Superolateral & 13 & Out \\
\hline 38 & Intermediate & Superolateral & Rear & Superolateral & 5 & $\ln$ \\
\hline 39 & Intermediate & Superolateral & Rear & Superolateral & 5 & Out \\
\hline 40 & Intermediate & Superolateral & Intermediate & Superolateral & 3 & Frontier \\
\hline 41 & Intermediate & Superolateral & Rear & Superolateral & 5 & Out \\
\hline 42 & Rear & Non-Superolateral & Rear & Superolateral & 9 & Out \\
\hline 43 & Rear & Superolateral & Rear & Superolateral & 13 & Out \\
\hline 44 & Rear & Superolateral & Rear & Superolateral & 13 & $\ln$ \\
\hline 45 & Rear & Superolateral & Intermediate & Non-Superolateral & 11 & $\ln$ \\
\hline 46 & Rear & Superolateral & Rear & Superolateral & 13 & Out \\
\hline 47 & Intermediate & Non-Superolateral & Rear & Superolateral & 2 & $\ln$ \\
\hline 48 & Rear & Superolateral & Intermediate & Superolateral & 10 & Frontier \\
\hline 49 & Intermediate & Superolateral & Rear & Superolateral & 5 & Out \\
\hline 50 & Intermediate & Superolateral & Intermediate & Superolateral & 3 & Frontier \\
\hline 51 & Rear & Non-Superolateral & Rear & Superolateral & 9 & Out \\
\hline 52 & Rear & Superolateral & Rear & Superolateral & 13 & Out \\
\hline 53 & Rear & Superolateral & Intermediate & Superolateral & 10 & Out \\
\hline
\end{tabular}


Table 4S: Longitudinal and transversal balance of contact pair-up (BCPU): Symmetric longitudinal BCPU means same or overlapped or adjacent longitudinal subdivisions (3 combined and 4 raw subdivisions); symmetric transversal BCPU means same or overlapped transversal subdivisions

\begin{tabular}{|c|c|c|c|c|c|c|c|c|c|c|}
\hline \multirow{2}{*}{\multicolumn{3}{|c|}{$\begin{array}{l}\text { Symetric and asymetric conditions } \\
\text { of longitudinal balance gathering }\end{array}$}} & \multicolumn{8}{|c|}{ Left subdivision } \\
\hline & & & Frontal & InterAnt/ & InterAnt & InterPost/ & InterPost & Rear/ & Rear & \\
\hline & & & matu & men & $\square+\square \square$ & $\square=\square$ & $\square \square \square$ & 口प⿴囗十 & प्वपघ & \\
\hline $\begin{array}{l}\text { Right } \\
\text { subdivision }\end{array}$ & $\begin{array}{l}\text { Frontal } \\
\text { InterAnt/Front } \\
\text { InterAnt } \\
\text { InterPost/InterAnt } \\
\text { InterPost } \\
\text { Rear/InterPost } \\
\text { Rear }\end{array}$ & 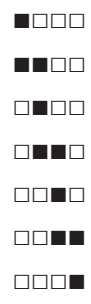 & $\begin{array}{l}\text { symmetric } \\
\text { symmetric } \\
\text { symmetric } \\
\text { symmetric } \\
\text { asymmetric } \\
\text { asymmetric } \\
\text { asymmetric }\end{array}$ & $\begin{array}{l}\text { symmetric } \\
\text { symmetric } \\
\text { symmetric } \\
\text { symmetric } \\
\text { symmetric } \\
\text { asymmetric } \\
\text { asymmetric }\end{array}$ & $\begin{array}{l}\text { symmetric } \\
\text { symmetric } \\
\text { symmetric } \\
\text { symmetric } \\
\text { symmetric } \\
\text { symmetric } \\
\text { asymmetric }\end{array}$ & $\begin{array}{l}\text { asymmetric } \\
\text { symmetric } \\
\text { symmetric } \\
\text { symmetric } \\
\text { symmetric } \\
\text { symmetric } \\
\text { asymmetric }\end{array}$ & $\begin{array}{l}\text { asymmetric } \\
\text { symmetric } \\
\text { symmetric } \\
\text { symmetric } \\
\text { symmetric } \\
\text { symmetric } \\
\text { symmetric }\end{array}$ & $\begin{array}{l}\text { asymmetric } \\
\text { asymmetric } \\
\text { asymmetric } \\
\text { symmetric } \\
\text { symmetric } \\
\text { symmetric } \\
\text { symmetric }\end{array}$ & $\begin{array}{l}\text { asymmetric } \\
\text { asymmetric } \\
\text { asymmetric } \\
\text { symmetric } \\
\text { symmetric } \\
\text { symmetric } \\
\text { symmetric }\end{array}$ & \\
\hline \multirow{3}{*}{\multicolumn{3}{|c|}{ Transversal balance gathering }} & \multicolumn{8}{|c|}{ Left subdivision } \\
\hline & & & SupLat & $\begin{array}{l}\text { SupLat/ } \\
\text { InfLat }\end{array}$ & Inflat & InfLat/InfMe & InfMed & $\begin{array}{l}\text { SupMed/ } \\
\text { InfMed }\end{array}$ & SupMed & $\begin{array}{l}\text { SupLat/ } \\
\text { SupMed }\end{array}$ \\
\hline & & & $\nearrow$ & $\rightarrow$ & $\searrow$ & $\downarrow$ & $\swarrow$ & $\leftarrow$ & $\nwarrow$ & $\uparrow$ \\
\hline \multirow{5}{*}{$\begin{array}{l}\text { Right } \\
\text { subdivision }\end{array}$} & SupLat & $\nearrow$ & symmetric & symmetric & asymmetric & asymmetric & asymmetric & asymmetric & asymmetric & symmetric \\
\hline & $\begin{array}{l}\text { SupLat/InfLat } \\
\text { InfLat }\end{array}$ & $\rightarrow$ & $\begin{array}{l}\text { symmetric } \\
\text { asymmetric }\end{array}$ & $\begin{array}{l}\text { symmetric } \\
\text { symmetric }\end{array}$ & $\begin{array}{l}\text { symmetric } \\
\text { symmetric }\end{array}$ & $\begin{array}{l}\text { asymmetric } \\
\text { symmetric }\end{array}$ & $\begin{array}{l}\text { asymmetric } \\
\text { asymmetric }\end{array}$ & $\begin{array}{l}\text { asymmetric } \\
\text { asymmetric }\end{array}$ & $\begin{array}{l}\text { asymmetric } \\
\text { asymmetric }\end{array}$ & $\begin{array}{l}\text { asymmetric } \\
\text { asymmetric }\end{array}$ \\
\hline & $\begin{array}{l}\text { InfLat/InfMed } \\
\text { InfMed }\end{array}$ & $\downarrow$ & $\begin{array}{l}\text { asymmetric } \\
\text { asymmetric }\end{array}$ & $\begin{array}{l}\text { asymmetric } \\
\text { asymmetric }\end{array}$ & $\begin{array}{l}\text { symmetric } \\
\text { asymmetric }\end{array}$ & $\begin{array}{l}\text { symmetric } \\
\text { symmetric }\end{array}$ & $\begin{array}{l}\text { symmetric } \\
\text { symmetric }\end{array}$ & $\begin{array}{l}\text { asymmetric } \\
\text { symmetric }\end{array}$ & $\begin{array}{l}\text { asymmetric } \\
\text { asymmetric }\end{array}$ & $\begin{array}{l}\text { asymmetric } \\
\text { asymmetric }\end{array}$ \\
\hline & $\begin{array}{l}\text { SupMed/InfMed } \\
\text { SupMed }\end{array}$ & $\leftarrow$ & $\begin{array}{l}\text { asymmetric } \\
\text { asymmetric }\end{array}$ & $\begin{array}{l}\text { asymmetric } \\
\text { asymmetric }\end{array}$ & $\begin{array}{l}\text { asymmetric } \\
\text { asymmetric }\end{array}$ & $\begin{array}{l}\text { asymmetric } \\
\text { asymmetric }\end{array}$ & $\begin{array}{l}\text { symmetric } \\
\text { asymmetric }\end{array}$ & $\begin{array}{l}\text { symmetric } \\
\text { symmetric }\end{array}$ & $\begin{array}{l}\text { symmetric } \\
\text { symmetric }\end{array}$ & $\begin{array}{l}\text { asymmetric } \\
\text { symmetric }\end{array}$ \\
\hline & SupLat/SupMed & $\uparrow$ & symmetric & asymmetric & asymmetric & asymmetric & asymmetric & asymmetric & symmetric & symmetric \\
\hline
\end{tabular}


Table 5S: Individual balance of contact pair-up (BCPU) of the 53 patients, ordered according to 6 BCPU conditions (see text)

\begin{tabular}{|c|c|c|c|c|c|c|c|}
\hline \multirow[t]{2}{*}{ Patient } & \multicolumn{3}{|c|}{ Raw aspect of BCPU } & \multicolumn{3}{|c|}{ Simplified aspect of BCPU } & \multirow{2}{*}{$\begin{array}{l}\text { BCPU } \\
\text { condition }\end{array}$} \\
\hline & longitudinal & Transversal & Membership & Iongitudinal & Transversal & Membership & \\
\hline 11 & INTERPOST-INTERANT/FRONT & asymmetric & asymmetric & Not-Rear & asymmetric & asymmetric & 0 \\
\hline 35 & asymmetric & $\begin{array}{l}\text { SUPLAT-SUPLAT/ } \\
\text { SUPMED }\end{array}$ & FRONTIER-OUT & asymmetric & Supero-Lateral & Out & 0 \\
\hline 53 & asymmetric & SUPLAT & FRONTIER-OUT & asymmetric & Supero-Lateral & Out & 0 \\
\hline 7 & $\begin{array}{l}\text { INTERANT-INTERPOST/ } \\
\text { INTERANT }\end{array}$ & asymmetric & OUT-FRONTIER & Not-Rear & asymmetric & Out & 0 \\
\hline 14 & $\begin{array}{l}\text { INTERPOST-INTERPOST/ } \\
\text { INTERANT }\end{array}$ & SUPLAT & asymmetric & Rear & Supero-Lateral & asymmetric & 0 \\
\hline 3 & $\begin{array}{l}\text { INTERPOST/ } \\
\text { INTERANT-INTERPOST }\end{array}$ & SUPLAT & asymmetric & Rear & Supero-Lateral & asymmetric & 0 \\
\hline 21 & REAR & asymmetric & asymmetric & Rear & asymmetric & asymmetric & 0 \\
\hline 8 & REAR & asymmetric & OUT & Rear & asymmetric & Out & 0 \\
\hline 41 & asymmetric & 2 & FRONTIER-OUT & asymmetric & Supero-Lateral & Out & 0 \\
\hline 6 & REAR-REAR/INTERPOST & asymmetric & FRONTIER-IN & Rear & asymmetric & Not-Out & 0 \\
\hline 12 & REAR-INTERPOST & $\begin{array}{l}\text { SUPMED-SUPLAT/ } \\
\text { SUPMED }\end{array}$ & asymmetric & Rear & Not Supero-Lateral & asymmetric & 0 \\
\hline 45 & REAR/INTERPOST-INTERPOST & asymmetric & FRONTIER-IN & Rear & asymmetric & Not-Out & 0 \\
\hline 36 & asymmetric & asymmetric & FRONTIER-OUT & asymmetric & asymmetric & Out & 0 \\
\hline 28 & REAR & asymmetric & OUT & Rear & asymmetric & Out & 0 \\
\hline 51 & REAR & asymmetric & OUT & Rear & asymmetric & Out & 0 \\
\hline 42 & REAR & asymmetric & OUT & Rear & asymmetric & Out & 0 \\
\hline 47 & INTERPOST/INTERANT-REAR & asymmetric & IN & Rear & asymmetric & Not-Out & 0 \\
\hline 34 & REAR-REAR/INTERPOST & SUPLAT & OUT & Rear & Supero-Lateral & Out & 1 \\
\hline 29 & REAR/INTERPOST-REAR & $\begin{array}{l}\text { SUPLAT-SUPLAT/ } \\
\text { SUPMED }\end{array}$ & FRONTIER-OUT & Rear & Supero-Lateral & Out & 1 \\
\hline 20 & INTERPOST & SUPLAT & FRONTIER-OUT & Rear & Supero-Lateral & Out & 1 \\
\hline 17 & INTERPOST & SUPLAT/SUPMED & OUT-FRONTIER & Rear & Supero-Lateral & Out & 1 \\
\hline 23 & $\begin{array}{l}\text { INTERPOST/INTERANT-REAR/ } \\
\text { INTERPOST }\end{array}$ & SUPLAT & FRONTIER-OUT & Rear & Supero-Lateral & Out & 1 \\
\hline 1 & REAR/INTERPOST-REAR & $\begin{array}{l}\text { SUPLAT-SUPLAT/ } \\
\text { SUPMED }\end{array}$ & FRONTIER-OUT & Rear & Supero-Lateral & Out & 1 \\
\hline 27 & REAR & SUPLAT & OUT & Rear & Supero-Lateral & Out & 1 \\
\hline 5 & INTERPOST/INTERANT-REAR & SUPLAT & FRONTIER-OUT & Rear & Supero-Lateral & Out & 1 \\
\hline 26 & REAR-INTERPOST & SUPLAT & OUT & Rear & Supero-Lateral & Out & 1 \\
\hline 25 & REAR-INTERPOST & SUPLAT & OUT-FRONTIER & Rear & Supero-Lateral & Out & 1 \\
\hline 43 & REAR-REAR/INTERPOST & SUPLAT & OUT & Rear & Supero-Lateral & Out & 1 \\
\hline 37 & REAR/INTERPOST-REAR & SUPLAT & OUT-FRONTIER & Rear & Supero-Lateral & Out & 1 \\
\hline 49 & INTERPOST/INTERANT-REAR & SUPLAT/SUPMED & FRONTIER-OUT & Rear & Supero-Lateral & Out & 1 \\
\hline 39 & INTERPOST-REAR & SUPLAT & OUT & Rear & Supero-Lateral & Out & 1 \\
\hline 52 & REAR & SUPLAT & OUT & Rear & Supero-Lateral & Out & 1 \\
\hline 46 & REAR & SUPLAT & OUT-FRONTIER & Rear & Supero-Lateral & Out & 2 \\
\hline 44 & REAR & $\begin{array}{l}\text { SUPLAT-SUPLAT/ } \\
\text { SUPMED }\end{array}$ & FRONTIER-IN & Rear & Supero-Lateral & Not-Out & 2 \\
\hline 33 & REAR/INTERPOST-INTERPOST & SUPLAT & FRONTIER-IN & Rear & Supero-Lateral & Not-Out & 2 \\
\hline 48 & REAR-INTERPOST & SUPLAT & FRONTIER & Rear & Supero-Lateral & Not-Out & 2 \\
\hline 38 & INTERPOST/INTERANT-REAR & SUPLAT & IN-FRONTIER & Rear & Supero-Lateral & Not-Out & 2 \\
\hline 19 & REAR & SUPLAT & FRONTIER & Rear & Supero-Lateral & Not-Out & 2 \\
\hline 2 & INTERPOST/INTERANT-REAR & SUPLAT/SUPMED & FRONTIER & Rear & Supero-Lateral & Not-Out & 2 \\
\hline 18 & REAR-INTERPOST & SUPLAT & FRONTIER & Rear & Supero-Lateral & Not-Out & 2 \\
\hline
\end{tabular}


Table 5S: Contd...

\begin{tabular}{|c|c|c|c|c|c|c|c|}
\hline \multirow[t]{2}{*}{ Patient } & \multicolumn{3}{|c|}{ Raw aspect of BCPU } & \multicolumn{3}{|c|}{ Simplified aspect of BCPU } & \multirow{2}{*}{$\begin{array}{c}\text { BCPU } \\
\text { condition }\end{array}$} \\
\hline & longitudinal & Transversal & Membership & longitudinal & Transversal & Membership & \\
\hline 9 & INTERPOST-REAR & $\begin{array}{l}\text { SUPLAT/ } \\
\text { SUPMED-SUPMED }\end{array}$ & OUT & Rear & Not Supero-Lateral & Out & 3 \\
\hline 15 & REAR-INTERPOST & $\begin{array}{l}\text { SUPLAT/ } \\
\text { SUPMED-SUPMED }\end{array}$ & OUT & Rear & Not Supero-Lateral & Out & 3 \\
\hline 13 & REAR-INTERPOST & $\begin{array}{l}\text { SUPMED/ } \\
\text { INFMED-INFMED }\end{array}$ & OUT-FRONTIER & Rear & Not Supero-Lateral & Out & 3 \\
\hline 31 & REAR & $\begin{array}{l}\text { SUPLAT/ } \\
\text { SUPMED-INFMED }\end{array}$ & FRONTIER-OUT & Rear & Not Supero-Lateral & Out & 3 \\
\hline 16 & $\begin{array}{l}\text { INTERPOST/ } \\
\text { INTERANT-INTERANT }\end{array}$ & $\begin{array}{l}\text { SUPLAT-SUPMED/ } \\
\text { SUPLAT }\end{array}$ & OUT & Not-Rear & Supero-Lateral & Out & 4 \\
\hline 10 & INTERANT-INTERPOST & SUPLAT & FRONTIER-OUT & Not-Rear & Supero-Lateral & Out & 4 \\
\hline 22 & INTERPOST-INTERANT & SUPLAT & FRONTIER-OUT & Not-Rear & Supero-Lateral & Out & 4 \\
\hline 40 & INTERANT-INTERPOST & $\begin{array}{l}\text { SUPLAT/ } \\
\text { SUPMED-SUPLAT }\end{array}$ & FRONTIER-FRONTIER & Not-Rear & Supero-Lateral & Not-Out & 5 \\
\hline 30 & INTERANT & $\begin{array}{l}\text { SUPLAT/ } \\
\text { SUPMED-SUPLAT }\end{array}$ & IN-FRONTIER & Not-Rear & Supero-Lateral & Not-Out & 5 \\
\hline 50 & INTERPOST/INTERANT & $\begin{array}{l}\text { SUPLAT-SUPLAT/ } \\
\text { SUPMED }\end{array}$ & FRONTIER & Not-Rear & Supero-Lateral & Not-Out & 5 \\
\hline 32 & $\begin{array}{l}\text { INTERANT-INTERPOST/ } \\
\text { INTERANT }\end{array}$ & SUPLAT & FRONTIER & Not-Rear & Supero-Lateral & Not-Out & 5 \\
\hline 4 & $\begin{array}{l}\text { INTERANT-INTERPOST/ } \\
\text { INTERANT }\end{array}$ & $\begin{array}{l}\text { SUPLAT/ } \\
\text { SUPMED-SUPLAT }\end{array}$ & IN-FRONTIER & Not-Rear & Supero-Lateral & Not-Out & 5 \\
\hline 24 & INTERPOST/INTERANT & SUPLAT & FRONTIER & Not-Rear & Supero-Lateral & Not-Out & 5 \\
\hline
\end{tabular}

Table 6S: Left-hemisphere-wise and right-hemisphere-wise most frequent contact pair-up (MFCP): rear-longitudinal MFCP, or 1-MFCP; 1-MFCP and SupLat-transversal MFCP, or 2-MFCP; 2-MFCP and out-STN-membership MFCP (3-MFCP); yes means that the contact fits the MFCP criteria (e.g. patient 12, the left contact fits 1-MFCP and the right contact fits 2-MFCP); * symmetric for the MFCP condition (see text for details)

\begin{tabular}{|c|c|c|c|c|c|c|}
\hline \multirow[t]{2}{*}{ Patient } & \multicolumn{3}{|c|}{ Left-hemisphere-wise MFCP } & \multicolumn{3}{|c|}{ Right-hemisphere-wise MFCP } \\
\hline & $\begin{array}{c}\text { Rear or Rear/ } \\
\text { Interpost or } \\
\text { Interpost: 1-MFCP }\end{array}$ & $\begin{array}{l}\text { 1-MFCP and SupLat } \\
\text { or SupLat/SupMed or } \\
\text { SupLat/InfLat: 2-MFCP }\end{array}$ & $\begin{array}{l}\text { 2-MFCP and Out } \\
\text { or Out-Frontier or } \\
\text { Frontier-Out: 3-MFCP }\end{array}$ & $\begin{array}{c}\text { Rear or Rear/ } \\
\text { Interpost or } \\
\text { Interpost: 1-MFCP }\end{array}$ & $\begin{array}{l}\text { 1-MFCP and SupLat } \\
\text { or SupLat/SupMed or } \\
\text { SupLat/InfLat: 2-MFCP }\end{array}$ & $\begin{array}{l}\text { 2-MFCP and Out } \\
\text { or Out-Frontier or } \\
\text { Frontier-Out: 3-MFCP }\end{array}$ \\
\hline 1 & yes $^{*}$ & yes $^{*}$ & yes* $^{*}$ & yes $^{*}$ & yes $^{*}$ & yes $^{*}$ \\
\hline 2 & & & & yes & yes & \\
\hline 3 & & & & yes & yes & \\
\hline \multicolumn{7}{|l|}{4} \\
\hline 5 & & & & yes & yes & yes \\
\hline 6 & yes $^{*}$ & yes & & yes $^{*}$ & & \\
\hline \multicolumn{7}{|l|}{7} \\
\hline 8 & yes $^{*}$ & yes & yes & yes $^{*}$ & & \\
\hline 9 & yes $^{*}$ & yes & yes & yes $^{*}$ & & \\
\hline 10 & & & & yes & yes & yes \\
\hline 11 & yes & yes & yes & & & \\
\hline 12 & yes $^{*}$ & & & yes* $^{*}$ & yes & \\
\hline 13 & yes $^{*}$ & yes & yes & yes $^{*}$ & & \\
\hline 14 & yes & yes & yes & & & \\
\hline 15 & yes $^{*}$ & yes & yes & yes $^{*}$ & & \\
\hline \multicolumn{7}{|l|}{16} \\
\hline 17 & yes $^{*}$ & yes* & yes $^{*}$ & yes* & yes $^{*}$ & yes* \\
\hline 18 & yes $^{*}$ & yes* & & yes $^{*}$ & yes $^{*}$ & \\
\hline 19 & yes $^{*}$ & yes $^{*}$ & & yes $^{*}$ & yes $^{*}$ & \\
\hline
\end{tabular}


Table 6S: Contd...

\begin{tabular}{|c|c|c|c|c|c|c|}
\hline \multirow[t]{2}{*}{ Patient } & \multicolumn{3}{|c|}{ Left-hemisphere-wise MFCP } & \multicolumn{3}{|c|}{ Right-hemisphere-wise MFCP } \\
\hline & $\begin{array}{c}\text { Rear or Rear/ } \\
\text { Interpost or } \\
\text { Interpost: 1-MFCP }\end{array}$ & $\begin{array}{l}\text { 1-MFCP and SupLat } \\
\text { or SupLat/SupMed or } \\
\text { SupLat/InfLat: 2-MFCP }\end{array}$ & $\begin{array}{l}\text { 2-MFCP and Out } \\
\text { or Out-Frontier or } \\
\text { Frontier-Out: 3-MFCP }\end{array}$ & $\begin{array}{c}\text { Rear or Rear/ } \\
\text { Interpost or } \\
\text { Interpost: 1-MFCP }\end{array}$ & $\begin{array}{l}\text { 1-MFCP and SupLat } \\
\text { or SupLat/SupMed or } \\
\text { SupLat/InfLat: 2-MFCP }\end{array}$ & $\begin{array}{l}\text { 2-MFCP and Out } \\
\text { or Out-Frontier or } \\
\text { Frontier-Out: 3-MFCP }\end{array}$ \\
\hline 20 & yes $^{*}$ & yes $^{*}$ & yes $^{*}$ & yes $^{*}$ & yes $^{*}$ & yes $^{*}$ \\
\hline 21 & yes $^{*}$ & yes & yes & yes $^{*}$ & & \\
\hline 22 & yes & yes & yes & & & \\
\hline 23 & & & & yes & yes & yes \\
\hline \multicolumn{7}{|l|}{24} \\
\hline 25 & yes $^{*}$ & yes $^{*}$ & yes $^{*}$ & yes $^{*}$ & yes $^{*}$ & yes* \\
\hline 26 & yes $^{*}$ & yes $^{*}$ & yes $^{*}$ & yes $^{*}$ & yes $^{*}$ & yes* \\
\hline 27 & yes $^{*}$ & yes $^{*}$ & yes $^{*}$ & yes $^{*}$ & yes $^{*}$ & yes* \\
\hline 28 & yes $^{*}$ & yes & yes & yes $^{*}$ & & \\
\hline 29 & yes $^{*}$ & yes $^{*}$ & yes $^{*}$ & yes $^{*}$ & yes $^{*}$ & yes* \\
\hline \multicolumn{7}{|l|}{30} \\
\hline 31 & yes $^{*}$ & yes & yes & yes $^{*}$ & & \\
\hline \multicolumn{7}{|l|}{32} \\
\hline 33 & yes* & yes* & & yes $^{*}$ & yes* & \\
\hline 34 & yes* & yes $^{*}$ & yes* & yes $^{*}$ & yes* & yes* \\
\hline 35 & & & & yes & yes & yes \\
\hline 36 & & & & yes & yes & yes \\
\hline 37 & yes* & yes $^{*}$ & yes* & yes $^{*}$ & yes* & yes* \\
\hline 38 & & & & yes & yes & \\
\hline 39 & yes $^{*}$ & yes* & yes $^{*}$ & yes $^{*}$ & yes* & yes* \\
\hline 40 & & & & yes & yes & \\
\hline 41 & & & & yes & yes & \\
\hline 42 & yes $^{*}$ & & & yes $^{*}$ & yes & yes \\
\hline 43 & yes $^{*}$ & yes $^{*}$ & yes* & yes $^{*}$ & yes* & yes* \\
\hline 44 & yes* & yes* & & yes* & yes* & \\
\hline
\end{tabular}

Table 7S: Analysis of voltage difference (left minus right hemisphere), medication (levodopa equivalent grugs,

LED; classes, $<-30 \%$, significant rise, $[-30 \%, 30 \%]$, no significant change, $>\mathbf{3 0} \%$, significant drop), age and gender according to unified contact location (UCL), longitudinal and transversal location (LonTran) and STN membership (Memb), and LonTran and Memb (Global); *, statistically significant

\begin{tabular}{|c|c|c|c|c|c|c|c|c|}
\hline \multirow[t]{3}{*}{ Patients $(n)$} & \multirow[t]{3}{*}{ UCL } & \multirow{3}{*}{$\begin{array}{c}\text { Voltage } \\
\text { difference }\end{array}$} & \multicolumn{4}{|c|}{ Medication (LED dose) } & \multirow[t]{3}{*}{ Age } & \multirow[t]{3}{*}{ Gender } \\
\hline & & & \multirow[t]{2}{*}{ Preop } & \multirow[t]{2}{*}{ 1-year } & \multicolumn{2}{|c|}{$\begin{array}{l}\text { Percentage of variation } \\
\text { (Preop -1-Year/Preop) }\end{array}$} & & \\
\hline & & & & & Dose & Class & & \\
\hline \multirow[t]{2}{*}{ All patients (53) } & LonTran & $0.88(53)$ & $0.32(53)$ & $0.14(51)$ & $0.69(51)$ & $0.97(51)$ & $0.80(53)$ & $0.91(53)$ \\
\hline & Memb & $0.69(53)$ & $0.17(53)$ & $0.03(51)^{*}$ & $0.2(51)$ & $0.43(51)$ & $0.48(53)$ & $0.28(53)$ \\
\hline \multirow[t]{2}{*}{ Most frequent LonTran UCL (36) } & LonTran & $0.71(36)$ & $0.17(36)$ & $0.36(34)$ & $0.95(34)$ & $0.95(34)$ & $0.88(36)$ & $0.76(36)$ \\
\hline & Memb & $0.65(36)$ & $0.14(36)$ & $0.13(34)$ & $0.54(34)$ & $0.47(34)$ & $0.54(36)$ & $0.12(36)$ \\
\hline Most frequent Global UCL (25) & Global & $0.83(25)$ & $0.2(25)$ & $0.45(24)$ & $0.54(24)$ & $0.90(24)$ & $0.36(25)$ & $0.43(25)$ \\
\hline
\end{tabular}




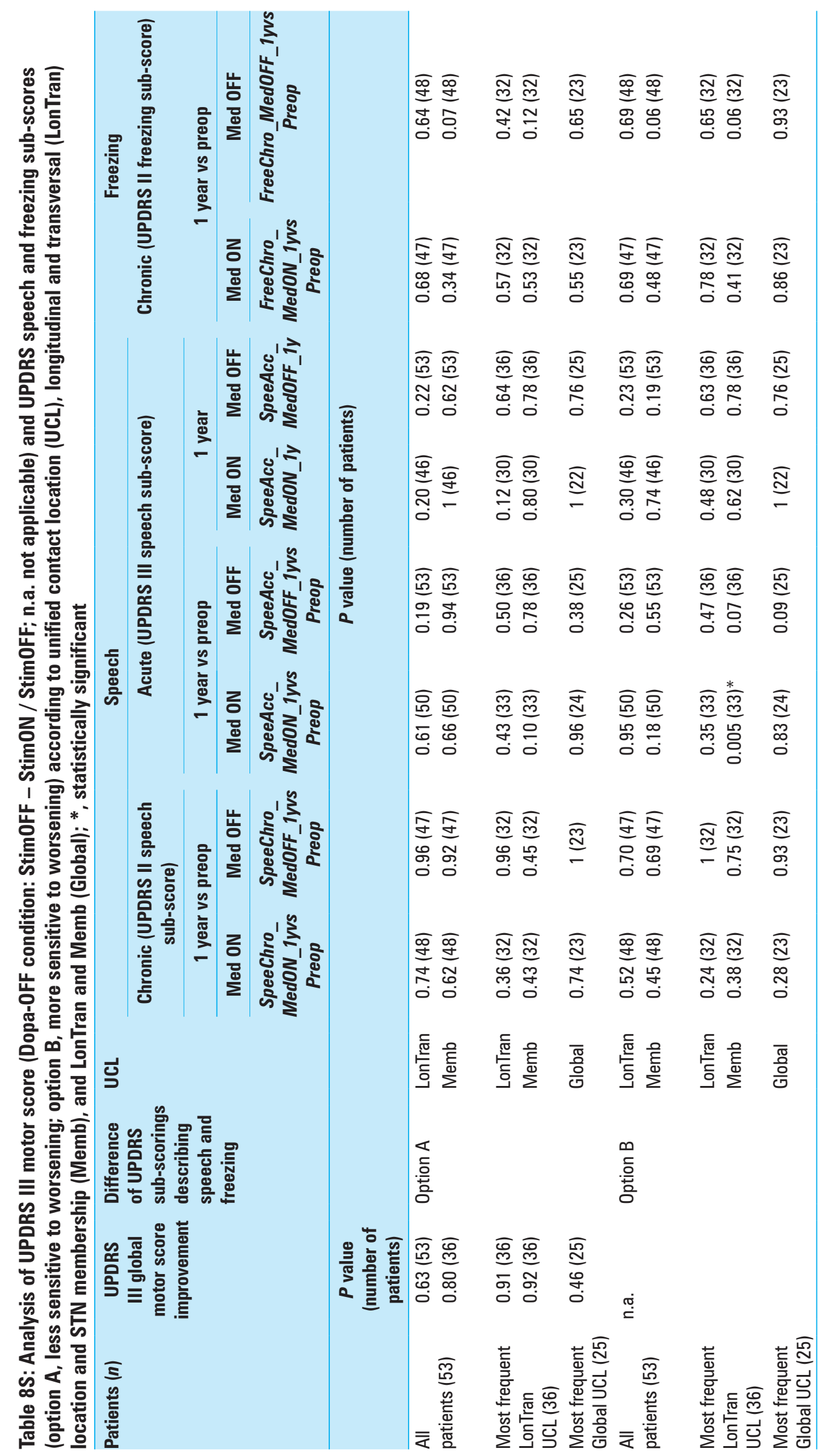


Table 9S: Analysis of voltage difference (left minus right hemisphere), medication (Levodopa equivalent drugs, LED; classes, $<-30 \%$, significant rise, $(-30 \%, 30 \%)$, no significant change, $>\mathbf{3 0} \%$, significant drop), age and gender according to balance of contact pair-up (BCPU) with 6 classes (BCPU0 to BCPU5, see text for details) or 3 classes (BCPU-asymmetric, BCPU-sym-Rear-SupLat-Out, and BCPU-sym-other; * statistically significant

\begin{tabular}{|c|c|c|c|c|c|c|c|c|}
\hline \multirow[t]{4}{*}{ Patients $(n)$} & \multirow[t]{4}{*}{ BCPU } & \multicolumn{7}{|c|}{$P$ value (number of patients) } \\
\hline & & \multirow[t]{3}{*}{ Voltage difference } & \multicolumn{4}{|c|}{ Medication (LED dose) } & \multirow[t]{3}{*}{ Age } & \multirow[t]{3}{*}{ Gender } \\
\hline & & & \multirow[t]{2}{*}{ Preop } & \multirow[t]{2}{*}{ 1-year } & \multicolumn{2}{|c|}{$\begin{array}{c}\text { Percentage of } \\
\text { variation (Preop -1- } \\
\text { Year/Preop) }\end{array}$} & & \\
\hline & & & & & Dose & Class & & \\
\hline \multirow[t]{2}{*}{ All patients (53) } & 6 classes & $0.65(53)$ & $0.11(53)$ & $0.28(5)$ & $0.17(50)$ & $0.11(50)$ & $0.63(53)$ & $0.31(53)$ \\
\hline & 3 classes & $0.53(53)$ & $0.03(53)^{*}$ & $0.15(50)$ & $0.43(50)$ & $0.11(50)$ & $0.62(53)$ & $0.16(53)$ \\
\hline
\end{tabular}




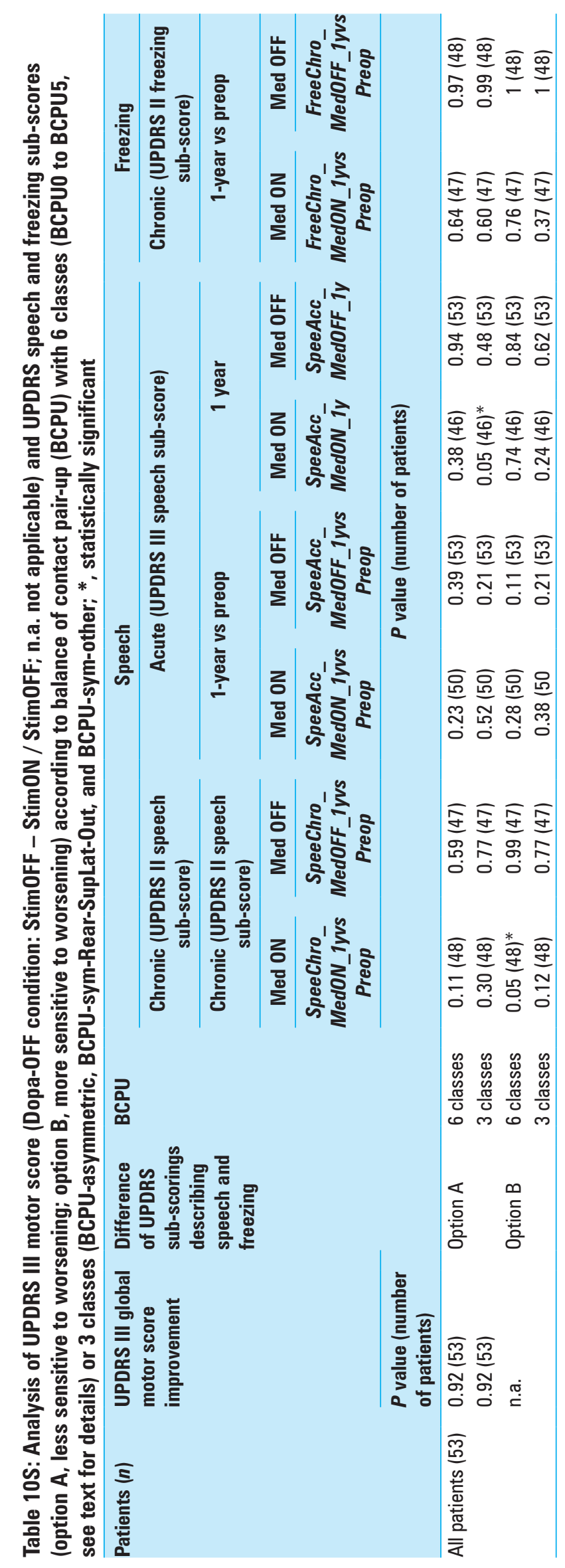


Table 11S: Analysis of voltage difference (left minus right hemisphere), medication (Levodopa equivalent drugs, LED; classes, $<-30 \%$, significant rise, [-30\%, 30\%], no significant change, $>\mathbf{3 0} \%$, significant drop), age and gender according to left-hemisphere-wise or right-hemisphere-wise laterality of the most frequent contact pair-ups (MFCP): first, only rear-longitudinal MFCP, named 1-MFCP, second, 1-MFCP and SupLat-transversal MFCP, named 2-MFCP, and third, 2-MFCP and out-STN-membership MFCP, named 3-MFCP; *, statistically significant

\begin{tabular}{|c|c|c|c|c|c|c|c|c|c|}
\hline \multirow[t]{4}{*}{ Patients $(n)$} & \multirow[t]{4}{*}{ hemisphere-wise } & \multirow[t]{4}{*}{ MFCP } & \multirow{3}{*}{$\begin{array}{c}\text { Voltage } \\
\text { difference }\end{array}$} & \multicolumn{4}{|c|}{ Medication (LED dose) } & \multirow[t]{3}{*}{ Age } & \multirow[t]{3}{*}{ Gender } \\
\hline & & & & \multirow[t]{2}{*}{ Preop } & \multirow[t]{2}{*}{ 1-year } & \multicolumn{2}{|c|}{$\begin{array}{c}\text { Percentage of variation } \\
\text { (Preop - 1-Year/Preop) }\end{array}$} & & \\
\hline & & & & & & dose & class & & \\
\hline & & & \multicolumn{7}{|c|}{$P$ value (number of patients) } \\
\hline \multirow[t]{6}{*}{ All patients $(n=53)$} & left & 1-MFCP & $0.95(53$ & $0.78(53)$ & $0.48(50)$ & $0.6650)$ & $0.92(50)$ & $0.56(53)$ & $0.19(53)$ \\
\hline & & 2-MFCP & $0.91(53)$ & $0.92(53)$ & $0.92(50)$ & $0.92(50)$ & $1(50)$ & $0.17(53)$ & $0.16(53)$ \\
\hline & & 3-MFCP & $0.39(53)$ & $0.71(53)$ & $0.39(50)$ & $0.48(50)$ & $0.93(50)$ & $0.12(53)$ & $0.05(53)^{*}$ \\
\hline & right & 1-MFCP & $0.95(53)$ & $0.03(53)^{*}$ & $0.49(50)$ & $0.83(50)$ & $0.79(50)$ & $0.12(53)$ & $0.40(53)$ \\
\hline & & 2-MFCP & $0.78(53)$ & $0.20(53)$ & $0.40(50)$ & $0.28(50)$ & $0.79(50)$ & $0.42(53)$ & $0.85(53)$ \\
\hline & & 3-MFCP & $0.97(53)$ & $0.37(53)$ & $0.46(50)$ & $0.24(50)$ & $0.47(50)$ & $0.93(53)$ & $0.03(53)^{*}$ \\
\hline
\end{tabular}




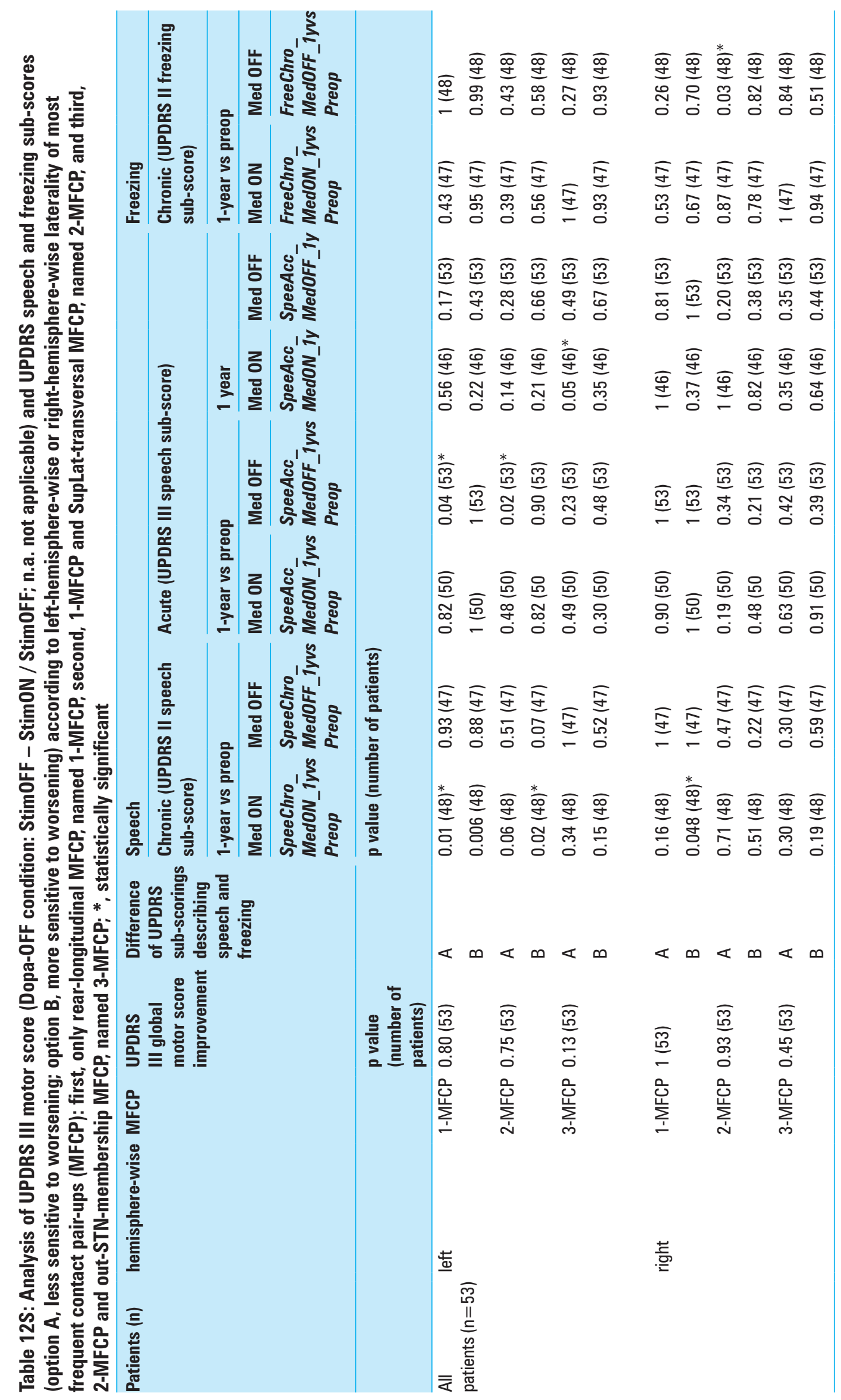

